Research Article

\title{
Effects of SWS Strength and Concrete Air Void Composite Defects on Performance of CFST Arch Bridge Rib
}

\author{
Zhengran Lu and Chao Guo iif \\ School of Civil Engineering, Shenyang Jianzhu University, No. 25, Hunnan Middle Road, Hunnan District, Shenyang City, \\ Liaoning 110168, China
}

Correspondence should be addressed to Chao Guo; guochaoglovel@126.com

Received 31 January 2020; Accepted 26 March 2020; Published 14 April 2020

Academic Editor: Francesco Tornabene

Copyright $(92020$ Zhengran Lu and Chao Guo. This is an open access article distributed under the Creative Commons Attribution License, which permits unrestricted use, distribution, and reproduction in any medium, provided the original work is properly cited.

\begin{abstract}
Most large-diameter concrete-filled steel tube (CFST) arch bridges adopt spiral-welded steel tubes for technical and economic reasons. However, during the steel tube manufacturing process, the welding temperature and other factors lead to a decreased spiral-welded seam (SWS) strength initially. Furthermore, for the CFST arch bridges using ordinary concrete, the laitance and air void defects inevitably appear, especially 20 years ago when there was no air-entraining agent in China. This paper presents a group of scale model experiments and finite element model analysis of the bearing capacity of a serviced CFST arch bridge rib with decreased SWS strength and concrete air void composite defects, under small eccentric axial compression on ultrasonic scanning field data. Parametric analyses were also performed to investigate the influence of the air void and SWS strength on the bearing capacity of the rib. Finally, a new ultimate strength index of the rib with composite defects was proposed, and a simplified formula was presented to estimate the effects of the air void and SWS strength decrease on the ultimate strength of the CFST arch bridge rib.
\end{abstract}

\section{Introduction}

Several concrete-filled steel tube (CFST) arch bridges, which have been used in China for many years, have formed part defects on the steel tube or concrete column imperfections during their service life or during manufacturing [1]. When high fluidity concrete is pumped into the steel tube, air voids and laitance coating inevitably appear, especially 20 years ago when there was no air-entraining agent in China. In harsh environments, particularly in the seasonal freeze-thaw zone where the temperature changes significantly, the air void rate of the core concrete expands. However, the defects caused by many factors such as initial construction conditions, service loads, and harsh environments are not single type of defects, but a combination of different defects. These are called composite defects, which shortens the bridge service life and may even finally lead to bridge collapse.

The Chang-Qing Hun River Bridge (Figure 1) in Shenyang city, Liaoning province, in the north of China, is an important part of the southern express road system and is of great significance for the environmental protection and economic development of the Shenyang region. It was constructed in 1997.

The main bridge has a net span of $120+140+120 \mathrm{~m}$. The bearing type of the Chang-Qing Hun River Bridge was a half-through CFST arch rib system. The height of the arch cross section is $2.4 \mathrm{~m}$. The arch width is $1.8 \mathrm{~m}$. Each rib consisted of four tubes with a diameter of $720 \mathrm{~mm}$. The thickness of the spiral-welded tube (SWT) is $10 \mathrm{~mm}$. The transverse and $\mathrm{K}$ shape support has the same diameter and thickness with the main arch ribs, as illustrated in Figure 2.

According to the requirements of Specifications for Design of Highway Concrete-Filled Steel Tubular Arch Bridges, SWTs are used here by welding the resulting abutting edges of a helically bending steel plate. The SWT is an economical tubing structure that can be used for longspan CFST arch bridge ribs. However, SWTs exhibit decreased welded seam strength compared to the base metal 


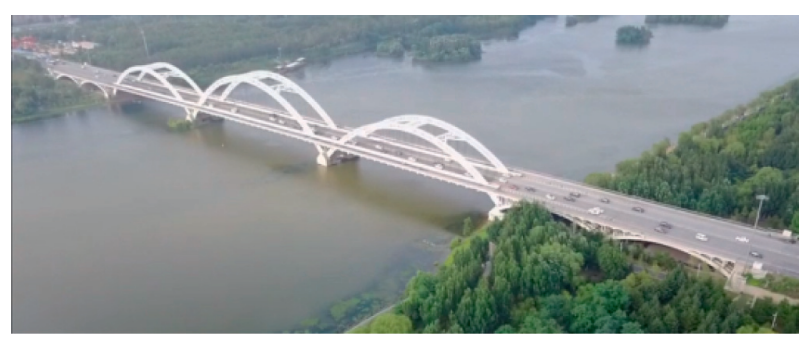

Figure 1: Chang-Qing Hun River Bridge.

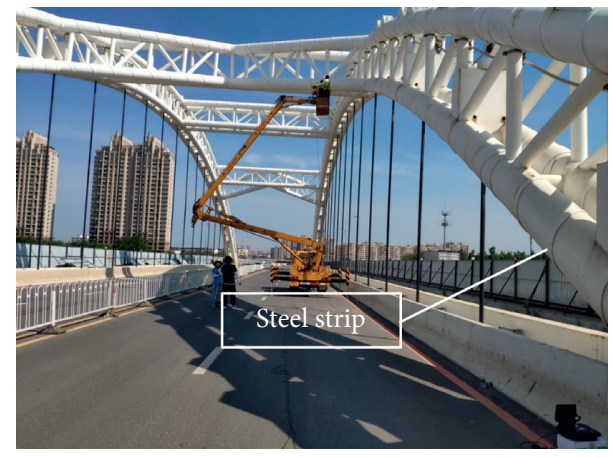

FIgURE 2: Details of CFST arch.

and, therefore, should be seemed as a single defect. Meanwhile, owing to the limitations of technical levels over 20 years ago, the spiral-welded seam (SWS) only penetrated $70 \%$. Many tests have been conducted on concrete-filled SWT columns, considering short and long column behavior, to estimate the applicability of existing guidelines for evaluating their strength and failure types $[2,3]$. Therefore, for the accurate evaluation of the bearing capacity of the Chang-Qing Hun River Bridge, the impact of SWS should be studied in depth.

Currently, the concrete poured into the CFST arch ribs is demanding air-entraining agent to avoid air voids and laitance coating in concrete core. However, research into improving the stability of entrained air in self-compacting concrete by optimizing the mix viscosity and air-entraining agent dosage was from 2017 [4], and the concrete used in Chang-Qing Hun River Bridge was ordinary concrete.

C50 concrete was designed to fill in the bridge tubes. However, owing to the limitations of the construction technology at that time, concrete segregation occurred, according to the core-taking test conducted onsite. In order to obtain the actual defects of concrete core column and the material properties of steel tube in the original CFST arch bridge transverse brace, firstly, a $60 \times 15 \mathrm{~cm}^{2}$ rectangular steel plate is cut at the top of the brace, and the core is drilled; then, the actual strength grade of the core column is calibrated by the unconfined compressive strength test.

In response to such threats, it is necessary to evaluate the stability of CFST arch bridges in regions with seasonal frost. In most cases, it can be effectively performed by detecting the imperfections of the CFSTs [5]. In this study, it was conducted by using an ultrasonic three-dimensional (3D) section scanning imager, MIRA A1040, made by ACSYS of
Russia, and the results are presented in Figure 3. The ratio of the interface gap area to the total tube area is approximately $3.6 \%$ to $30.5 \%$, and the signal anomaly area depth is approximately to the core. Ultrasonic nondestructive testing technology has been used extensively for the defect inspection of concrete structures in civil engineering. In particular, its reliability of test results has been proven by a large number of indoor tests on CFST defects [6-11].

Over the past two decades, many numerical and experimental studies have been carried out on CFST ribs under axial loading using the finite element model (FEM). Han et al. [12], Srinivasan and Schneider [13], Hu et al. [14], and Ellobody and Young [15] constructed an elastic-toplastic FEM for CFST columns with a square or circular section. Tao et al. [16, 17], Hassanein [18], and Ellobody and Young [19] carried out a nonlinear FEM on CFST short or long columns. Dai and Lam [20] established a nonlinear FEM for the analysis of CFST columns with an elliptical section. Huang et al. [21] and $\mathrm{Hu}$ and $\mathrm{Su}$ [22] used ABAQUS to conduct nonlinear analysis on the behavior of CFST columns. Jaishi and Ren [23] established a halfthrough arch bridge linear FEM by means of two-node beam elements using ANSYS.

The majority of the above analyses have focused on straight-welded or seamless small-diameter CFSTs, ignoring the influences of the concrete segregation, air voids in concrete, and SWS strength composite defects on their bearing performance. However, actual CFSTs, particularly large-diameter CFST arch bridges that are in service in cold areas, will inevitably be affected by the above defects. Thus far, single-factor defects of CFST ribs have been studied by Liao et al. [24, 25], Han et al. [26, 27], Liu et al. [28], and Huang et al. [29]. They performed a series of experiments and established FEMs for analytical investigations to estimate the circumferential and cap gaps, where the key calculating parameter was the section gap ratio. On this basis, the influence analysis of concrete air void ratio $(\alpha)$ on CFST bearing capacity is supplemented in this paper.

For a CFST rib with concrete air void, as illustrated in Figure 4,

$$
\alpha=\frac{V_{\text {air-void }}}{V_{c}},
$$

where $V_{\text {air-void }}$ is the volume of the air void in the concrete core, as indicated in Figure 5, and $V_{c}$ is the volume of the cylinder where the concrete may be vibrated without compacting.

In this research, a series of nonlinear FEM analyses of a CFST arch bridge transverse brace element (which has a distance of $3 \mathrm{~m}$ between two vertical braces) with air voids and SWS strength decreased composite defects under eccentric axial compression. First, a no-defect 3D elastic-toplastic FEM is developed, in which only the nonlinear material constitutive model is included. Second, the bearing capacity of the CFST ribs with a single defect, namely, the decreased SWS strength and air void, is studied. Third, the brace with composite defects was examined, and finally, its ultimate strength was evaluated. 


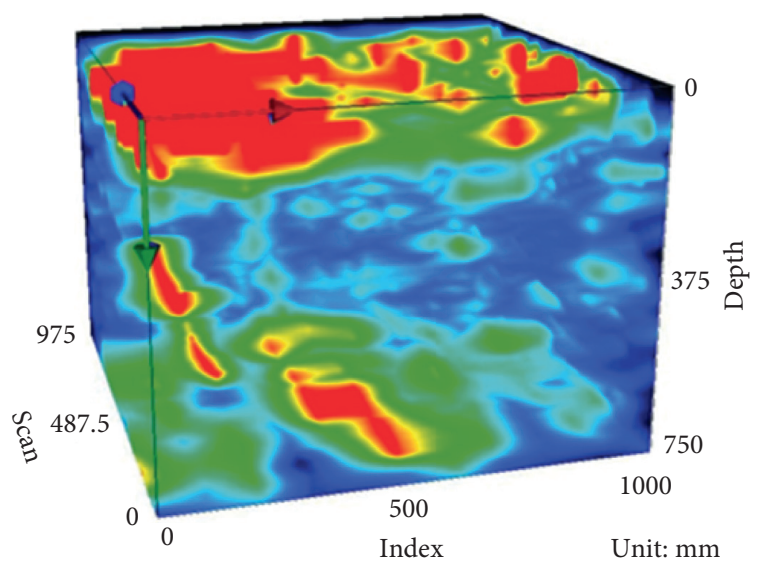

(a)

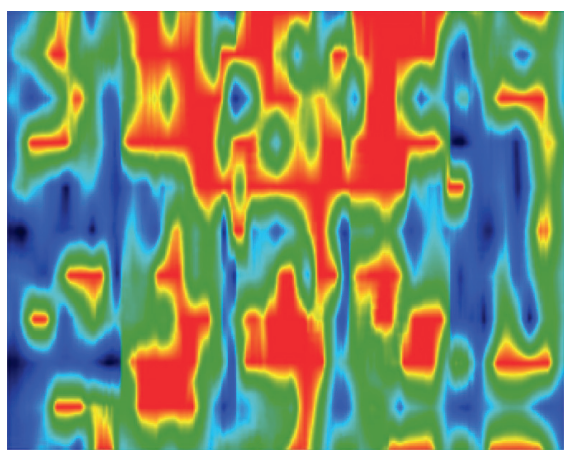

(b)

FIGURE 3: Ultrasonic scanning imagery of CFST: (a) 3D section scanning imagery; (b) plane scanning imagery.

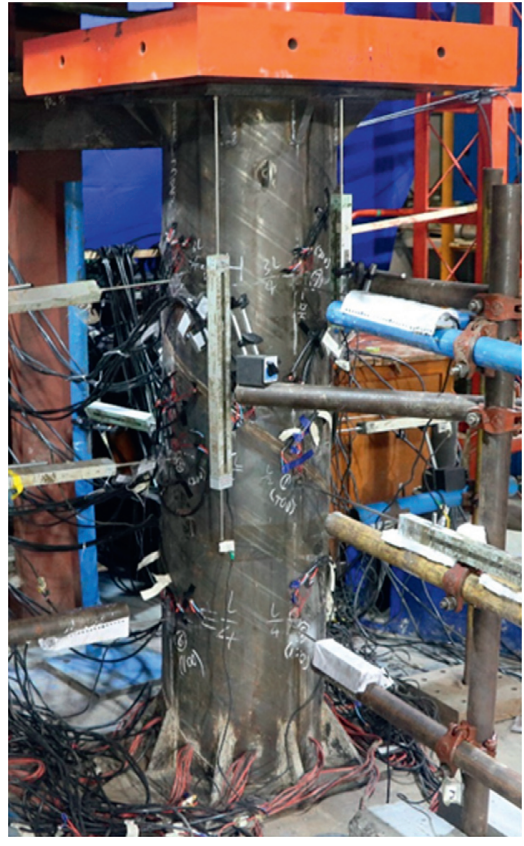

(a)

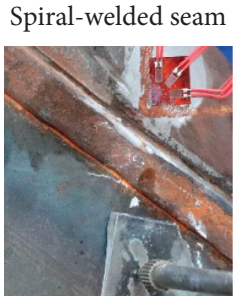

(b)

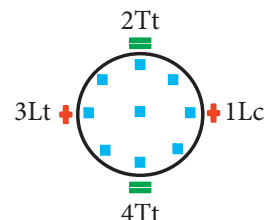

(c)

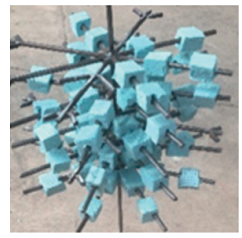

$V_{\text {air-void }}$

(d)

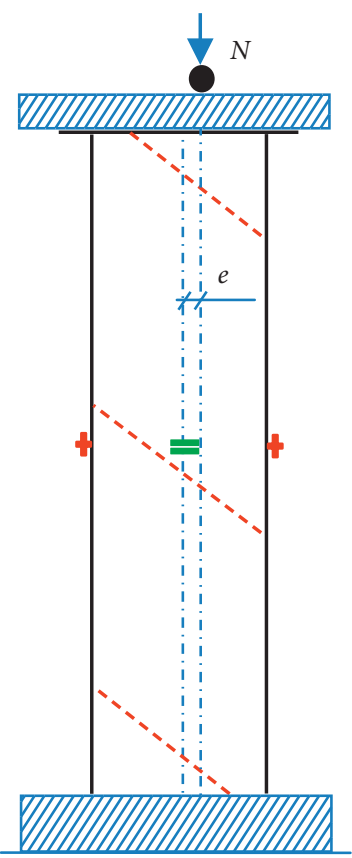

(e)

Figure 4: Test principle.

\section{Experimental Investigation and Program}

2.1. General Condition of Specimens. Sixteen CFST specimens were fabricated and tested under eccentric compression loading. The test parameters were the SWS strength (SWS-S) and concrete air void ratio $(\alpha)$.

Geometrical scale of $1 / 2$ is adopted, so the length $L$ of all specimens was $1500 \mathrm{~mm}$. The outer diameter $D$ of the steel tubes was $360 \mathrm{~mm}$, and the corresponding wall thickness $t$ was $5 \mathrm{~mm}$, respectively, according to similarity ration $1 / 2$ of the Chang-Qing Hun River Bridge arch ribs.

The SWS-S considered in this paper was $80 \%, 65 \%$, and $50 \%$ of the base metal. SWS-S reduction was achieved by grooving the steel tube around the spiral weld and changing the depth of the groove, as shown in Figure 4(b). For example, 80\% of the strength is achieved by cutting $1 \mathrm{~mm}$ deep spiral groove on the base metal. At this time, the remaining wall thickness of the steel pipe is $4 \mathrm{~mm}$ so that the strength of the SWS is reduced $80 \%$ relative to base metal. Similarly, $65 \%$ and $50 \%$ of the SWS$\mathrm{S}$ are achieved by cutting $1.5 \mathrm{~mm}$ and $2.0 \mathrm{~mm}$ deep spiral groove on the base metal, respectively.

$\alpha$ was $10 \%, 20 \%$, and $30 \%$ of the core concrete section. The distribution range of concrete air void was within a height of $0.2-0.6 \mathrm{~m}$ regions taking the height center line as axis of symmetry. Lots of cube foam blocks with the length of $2 \mathrm{~cm}$ were used to simulate the air void of concrete. The numbers of cube foam blocks in each specimen could be calculated through equation (1). A steel skeleton frame 


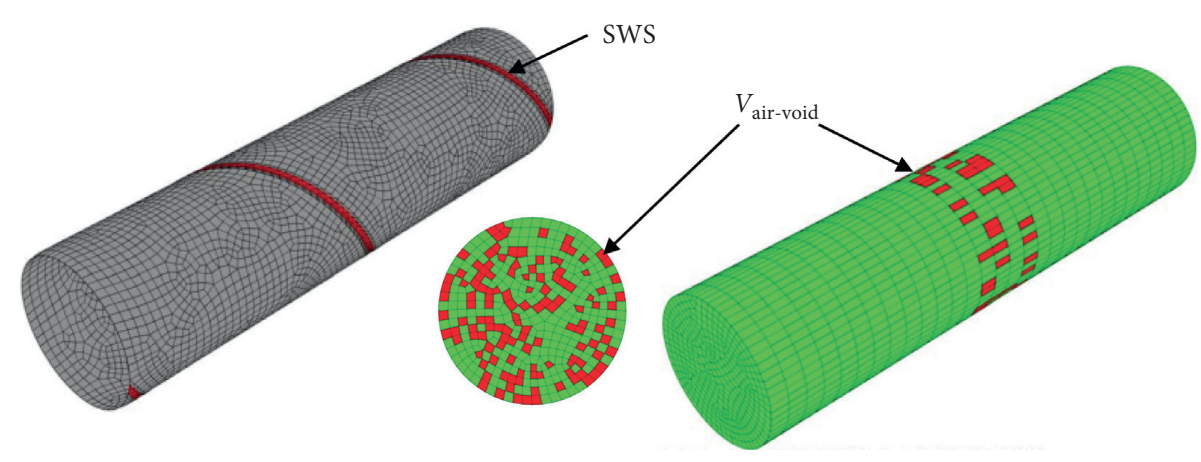

Figure 5: Mesh of CFST composite defects.

shown as Figure 4(d) was welded to the base plate and fixed in the center of steel tube. The cube foam blocks fastened to the steel bar occupying the location of the concrete to be poured, so as to realize the goal of simulating the concrete core air void.

The loading eccentricity $e$ as shown in Figure 4(e) was set to be $57 \mathrm{~mm}$, and it was approximately 0.15 times of the tube's outer diameter.

All of the specimen information is listed in Table 1. The specimen labels in Table 1 followed the following rules: (1) the first character A stands for air void; (2) the second numerical value represents the air void ratio $(\alpha)$; $(3)$ character S stands for SWS-S; and (4) the last number after the S stands for the strength percent of the base metal.

2.2. Test Setup and Instrumentation. The tests were performed on a $10000 \mathrm{kN}$ capacity testing machine in the laboratory of Shenyang Jianzhu University. The test setup and principle are shown in Figure 4. All specimens were tested as plane-ended support that was achieved by using the plates with a sphere hinge on top end of the specimens, and the bottom was fixed on the ground.

The testing machines were preadjusted, aligning the specimens to make sure that the middle of loading plate aligns with the loading line, as shown in Figure 4(e).

All the specimens were loaded until the load dropped below $70 \%$ of its peak value or the axial deformation reached $75 \mathrm{~mm}$, which was $1 / 20$ of the specimen length $L$.

To measure exactly deformation of specimen and get the principal strain, the right-angle strain flowers were used to measure the longitudinal, transverse, and diagonal strains. The right-angle strain flowers were pasted on the surface of steel tube at the locations of $L / 4, L / 2$, and $3 L / 4 \mathrm{~mm}$, respectively, for each specimen. Each specimen was instrumented with twelve right-angle strain flowers. The locations and numbering scheme for the above gauges are depicted in Figure 4(c). In Figure 4(c), the direction of the compressed area is numbered 1, and the direction of tensiled area is numbered 3. To obtain the effect of decreased SWS strength on the bearing capacity of specimen, the position of spiral groove was set in the midheight of the compressive zone, and the detail is shown in Figure 4(b).

Twelve displacement transducers (LVDTs) were employed to record the lateral deflection. LVDTs were evenly set at the midheight and the other two quartiles of the specimen, respectively. Four LVDTs were set up at the top to measure the total axial deformation of the specimen. All of the transducers were calibrated before the test. The rightangle strain flowers and the LVDTs were all connected to the data acquisition system, and the readings were recorded automatically throughout the testing.

At the initial stage, the load-control mode was adopted. The multistage loading with each step $50 \mathrm{kN}$ holding 10 minutes was used to make the component stressed evenly and also to be convenient to observe and record the test phenomenon. When the specimen reached the yield load, the loading mode changed to displacement-control mode, and the loading rate is $0.4 \mathrm{~mm} / \mathrm{min}$ until the specimen was damaged.

\subsection{Experimental Results and Discussion}

2.3.1. Testing Phenomenon and Analysis. In the progress of the test, deformation of specimen was not obvious at the preliminary stage of loading, and bearing capacity $(N)$ was in linear relation with average axial strain $(\varepsilon)$.

For the specimens with more reduced SWS-S, when load attained $50 \% \sim 60 \%$ of ultimate bearing capacity, the growth rate of load apparently slowed. Continuous sharp and snapping clack came from the core concrete during the test.

When load attained the peak value, it was followed by a descend trend, and the steel tube with spiral groove began to show clear signs of wall buckling. The first local buckling occurred at the midheight of the compressive zone with higher apparent distortions and became more and more obvious. The local buckling extends in a ring.

2.3.2. Failure Modes. The specimens with and without SWS$S$ and air void composite defects exhibited clearly different failure modes. Outward local buckling occurred in all the CFST column specimens, accompanied by overall lateral deflection observed at the midheight. Local buckling which is similar to the elephant foot shape occurred at the root of the specimen. The specimens with a SWS-S decreased also showing fold local buckling at the midheight of the compressive zone. The typical failure modes of the specimens are shown in Figure 6. The specimens with air void in the concrete column core show more local external protrusion 
TABLE 1: Specimen information.

\begin{tabular}{lccccccccc}
\hline Number & Specimen label & $\alpha$ & SWS-S $(\%)$ & $N_{e}(\mathrm{kN})$ & $N_{n}(\mathrm{kN})$ & $\mathrm{SI}_{e}$ & $\mathrm{SI}_{n}$ & $\Delta u_{e}(\mathrm{~mm})$ & $\Delta u_{n}(\mathrm{~mm})$ \\
\hline 1 & A0S100 & 0 & 100 & 5582 & 5800 & 1 & 1 & 14.0 \\
2 & A0S80 & 0 & 80 & 5521 & 5788 & 0.989 & 0.998 & 14.1 & 8.0 \\
3 & A0S65 & 0 & 65 & 5476 & 5777 & 0.981 & 0.996 & 14.2 \\
4 & A0S50 & 0 & 50 & 5426 & 5794 & 0.972 & 0.995 & 14.3 \\
5 & A1S100 & 0.1 & 100 & 5359 & 5735 & 0.960 & 0.989 & 15.8 & 7.0 \\
6 & A1S80 & 0.1 & 80 & 5351 & 5756 & 0.958 & 0.992 & 16.0 & 8.0 \\
7 & A1S65 & 0.1 & 65 & 5331 & 5748 & 0.955 & 0.991 & 15.8 \\
8 & A1S50 & 0.1 & 50 & 5275 & 5741 & 0.945 & 0.990 & 15.8 & 8.1 \\
9 & A2S100 & 0.2 & 100 & 5108 & 5315 & 0.915 & 0.916 & 15.9 \\
10 & A2S80 & 0.2 & 80 & 5052 & 5366 & 0.905 & 0.925 & 15.0 \\
11 & A2S65 & 0.2 & 65 & 5030 & 5356 & 0.901 & 0.923 & 14.1 \\
12 & A2S50 & 0.2 & 50 & 5018 & 5356 & 0.899 & 0.923 & 14.3 & 8.0 \\
13 & A3S100 & 0.3 & 100 & 4845 & 4884 & 0.868 & 0.842 & 14.2 \\
14 & A3S80 & 0.3 & 80 & 4812 & 4880 & 0.862 & 0.841 & 14.0 \\
15 & A3S65 & 0.3 & 65 & 4801 & 4872 & 0.860 & 0.840 & 14.1 & 7.1 \\
16 & A3S50 & 0.3 & 50 & 4773 & 4837 & 0.855 & 0.834 & 14.1 \\
\hline
\end{tabular}

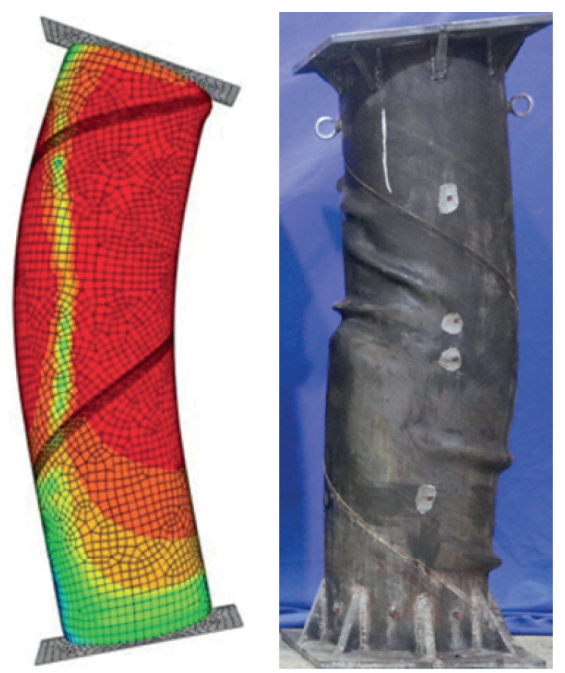

(a)
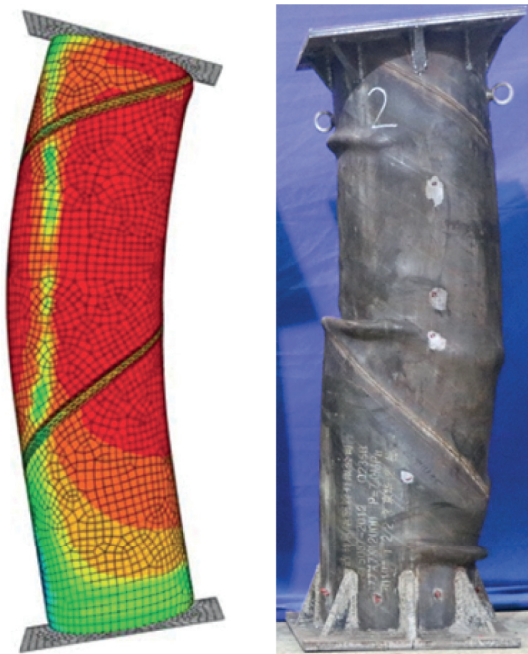

(b)
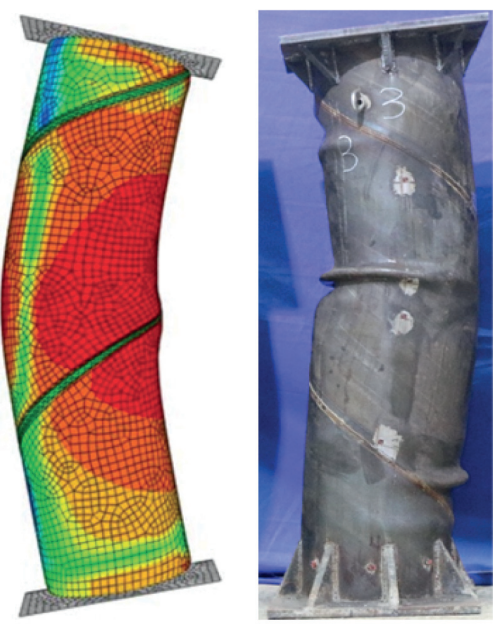
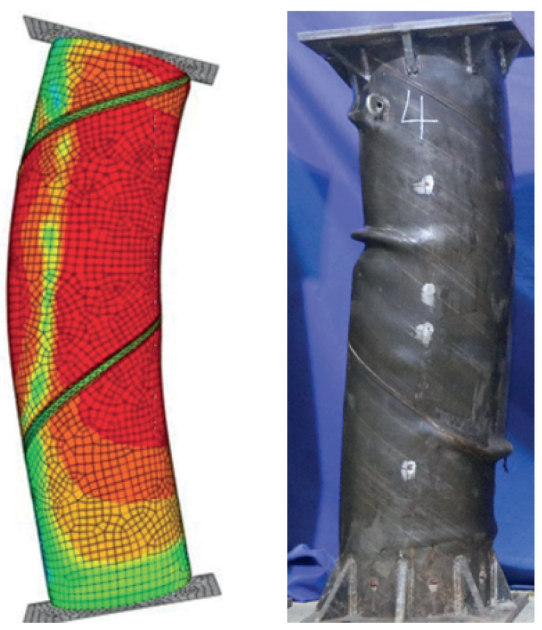

(c)

(d)

Figure 6: Failure modes of specimens: (a) CFST without defects; (b) SWS-S $=80 \%$ and $\alpha=10 \%$; (c) SWS-S $=65 \%$ and $\alpha=20 \%$; (d) SWS$\mathrm{S}=50 \%$ and $\alpha=30 \%$. 
characteristics. It could be found that the more the air void rate specimens have, the more the overall buckling deformation was observed. However, the SWS-S and air void have varying degrees influence on the failure modes CFST specimens under eccentrical load.

\subsubsection{Axial Load (N) versus Axial Strain (E) Responses.} All the tested specimens with and without composite defects showed an overall similar failure process and behaved in a perfect ductile manner. However, the specimens with a high air void rate in core concrete had clearly a different failure process. While the specimens experience an axial deformation of about $14 \mathrm{~mm}$, an abrupt drop in load occurred. Figure 7 shows the axial load $(N)$ versus axial strain $(\varepsilon)$ curves of the specimens with different defects.

The $N-\varepsilon$ curves of the perfect CFST are shown in Figure $7(\mathrm{a})$. It could be found that the perfect CFST specimen had a significant stiffness. The bearing capacity of CFST decreases slowly due to the second-order effect as the local buckling develops. In the $N-\varepsilon$ curve, the above results in appearance of slow-descending branch.

In the $N-\varepsilon$ curves of the CFST specimens with composite defects (Figures $7(\mathrm{~b})-7(\mathrm{~d})$ ), there are many stages that yield during the whole loading process. Because of the air voids in the concrete, it is easy to be crushed, and the crushed concrete comes into expansion that contacts with the steel tube again. Both of them bear the force together, which makes the bearing capacity rise. Generally, the air void rates have significant effects on the $N-\varepsilon$ curves, no matter how the eccentrically loaded CFST specimens are.

A typical $N-\varepsilon$ curve for the CFST specimen with composite defects is depicted in Figure 7. Parts of typical $N-u$ curves for the specimens with different composite defects are shown in Figure 8.

The measured ultimate strengths $\left(N_{u}\right)$ of all the tested specimens are listed in Table 1 . In Table $1, \Delta u_{e}$ and $\Delta u_{n}$ are the axial deformation and lateral deflection corresponding to the peak load $\left(N_{u}\right)$, respectively.

For quantitative evaluation of the influence of the SWS-S and air void rates on the CFST bearing capacity, a strength index SI is defined and calculated as follows:

$$
\mathrm{SI}=\frac{N_{c-\text { def }}}{N_{n-\text { def }}},
$$

where $N_{c-\text { def }}$ is the maximum value of the CFST rib $N-\varepsilon$ curves with SWS-S and air void composite defects and $N_{n \text {-def }}$ is the maximum value of the CFST rib $N-\varepsilon$ curves without defects. The subscript " $e$ " represents experiment data, and " $n$ " represents FEM calculated results in Table 1. When the SI of the CFST does not consider the reduction in the SWS strength, it is close to the results of Hassanein [18], Ellobody and Young [15], and Dai and Lam [20], but the air void rates of this bridge were the key defects, and it had much higher effects than the above experimental level, so the coverage area of the experiment data was larger.

2.3.4. Strain Analysis. The transverse and longitudinal strains of extreme steel fibers at midheight of the CFST rib specimens are presented in Figures 9 and 10. In these two figures, $\varepsilon \mathrm{Lc}$ and $\varepsilon \mathrm{Lt}$ denote the longitudinal strains at the compressive and tensile side of the specimen (as shown in Figure 5, 1Lc and 3Lt); $\varepsilon$ Tt denotes the transverse strains at the profile tensile side of the specimen, respectively (as shown in Figure 5,2Tt and 4Tt). The values of tensile strains are set to be positive and the compressive negative ones in the above figures. In Figure 9, it could be found that both $\varepsilon \mathrm{Lc}$ and $\varepsilon$ Lt of the CFST specimens without composite defects exceed the steel yield strain $(\varepsilon y$, the measured value is $1,920 \mu \varepsilon$ ) as the ultimate strength $N_{u}$ is reached, and the magnitudes of $\varepsilon$ Lc and $\varepsilon$ Lt corresponding to $N_{u}$ are $-5,888$ and $2,119 \mu \varepsilon$, respectively. For the specimens that have composite defects, the trend of strain development is generally similar with that of the specimen perfect. However, because of the existence of defect, lower magnitudes of $\varepsilon \mathrm{Lc}$ and $\varepsilon$ Lt referencing to $N_{u}$ were achieved. With a higher air void ratio $(\alpha)$ and lower SWS-S, the CFST specimen with A ends to have a lower $\varepsilon$ Lc and $\varepsilon$ Lt at the peak load. The magnitudes of $\varepsilon \mathrm{Lt}$ for the CFST specimens with an air void ratio of $10 \%$ and $20 \%$ at the peak load are 600 and $800 \mu \varepsilon$, respectively, which approaches the perfect CFST level. For the CFST specimens with an air void ratio of $30 \%$, the trend of the strain development is different from that of the CFST specimen with less level composite defects. The $N$ - $\varepsilon$ Tt curves of the CFST specimen with an air void ratio of $30 \%$ experienced a high yield scope, as shown in Figure 10, the trend of which is similar to the corresponding $N-u$ curves, and the main reason is possibly because of the crushing of the core concrete.

\section{Numerical Analysis}

\subsection{Material Properties and Constitutive Models}

3.1.1. Steel. The parameters of the steel tube in this case are presented in Table 2. Figure 11 shows the steel specimen with weld defects.

Many stress $(\sigma)$-strain $(\varepsilon)$ models have been used by different researchers for the steel tube, including the linear elastic perfectly plastic model with multicurve hardening [12]. Steel exhibits less strain-hardening at strains of general structural interest scope $(\varepsilon<0.05)$. Very approximated axial stress-strain curves can be obtained by using different $\sigma-\varepsilon$ models for steel. The mathematic model of the $\sigma-\varepsilon$ relationship of a steel tube has little influence on the bearing capacity of rib and only affects the load-strain curve slightly at a postpoint stage for the confined concrete core. However, the different $\sigma-\varepsilon$ relationships of steel have a little influence on the load-strain curves of CFST rib at strains of interest in the arch bridge. Particularly, for the arch bridge structure with a span of $150 \mathrm{~m}$ investigated in this study, a small strain will lead to changes in the bridge stiffness. A $\sigma-\varepsilon$ model was proposed by Tao et al. [30] for steel tube with a validity strength range from 200 to $800 \mathrm{MPa}$. According to the tensile test of the steel tube specimen, the $\sigma-\varepsilon$ relationship of the steel tube in this research obeys a trilinear material property model, as illustrated in Figure 12. 


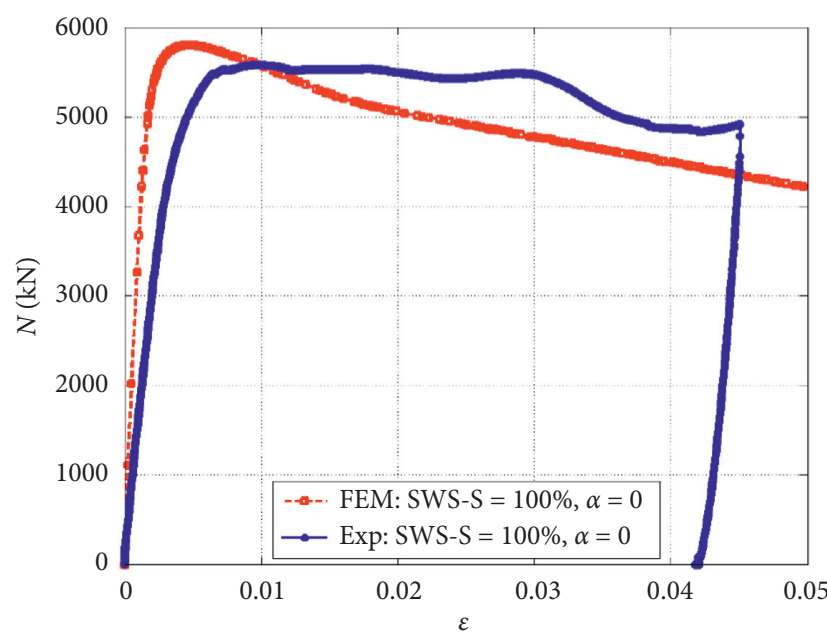

(a)

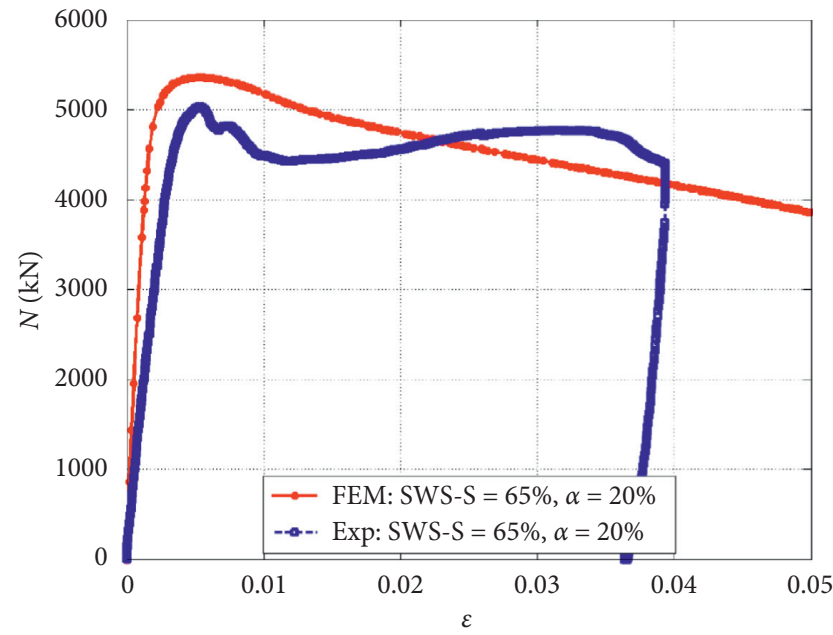

(c)

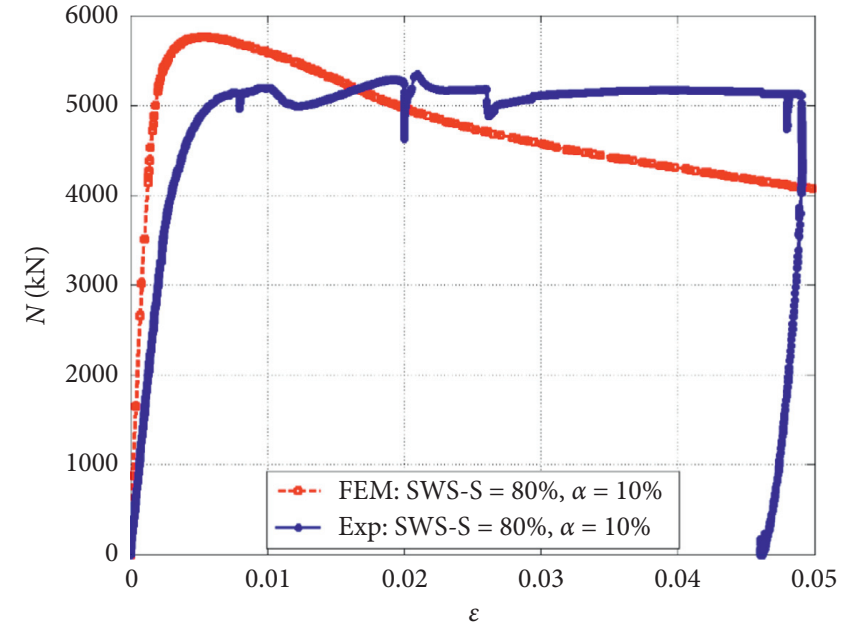

(b)

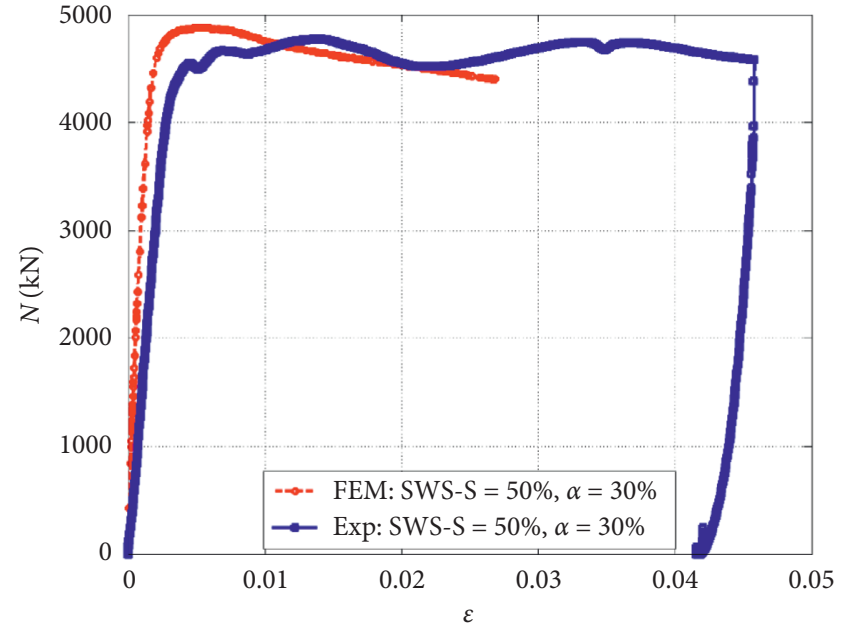

(d)

FIGURE 7: Axial load $(N)$ versus axial strain ( $(\varepsilon)$ relationships: (a) CFST without defects; (b) SWS-S $=80 \%$ and $\alpha=10 \%$; (c) SWS-S $=65 \%$ and $\alpha=20 \%$; (d) SWS-S $=50 \%$ and $\alpha=30 \%$.

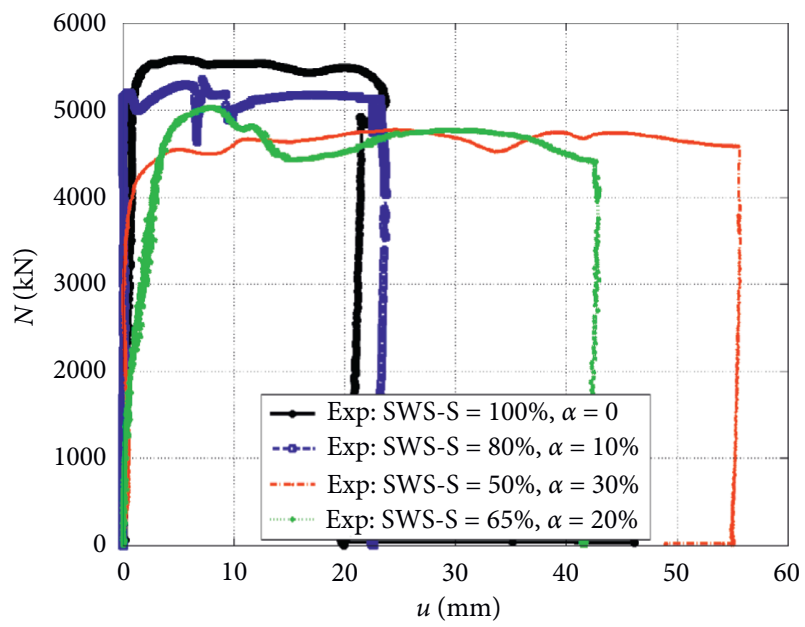

Figure 8: Axial load $(N)$ versus lateral displacement $(u)$.

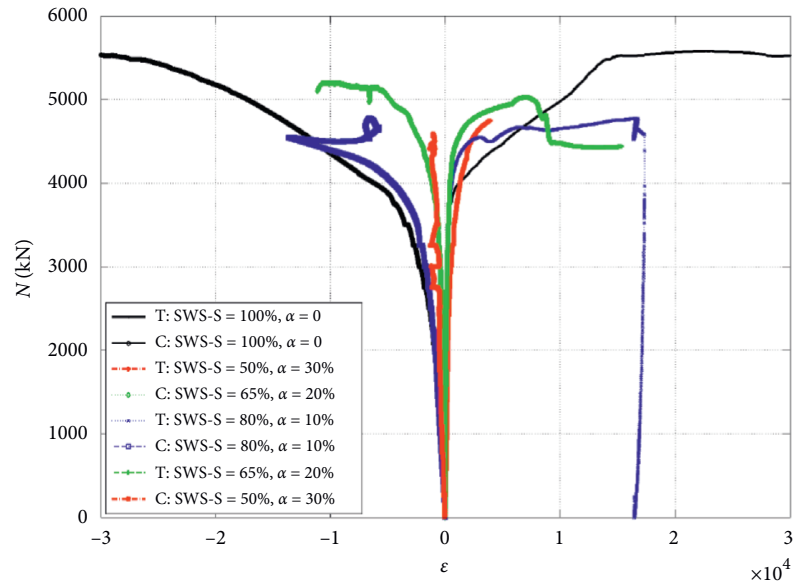

Figure 9: Axial load $(N)$ versus longitudinal strain $(\varepsilon L c / t)$ at midheight of the specimens. 


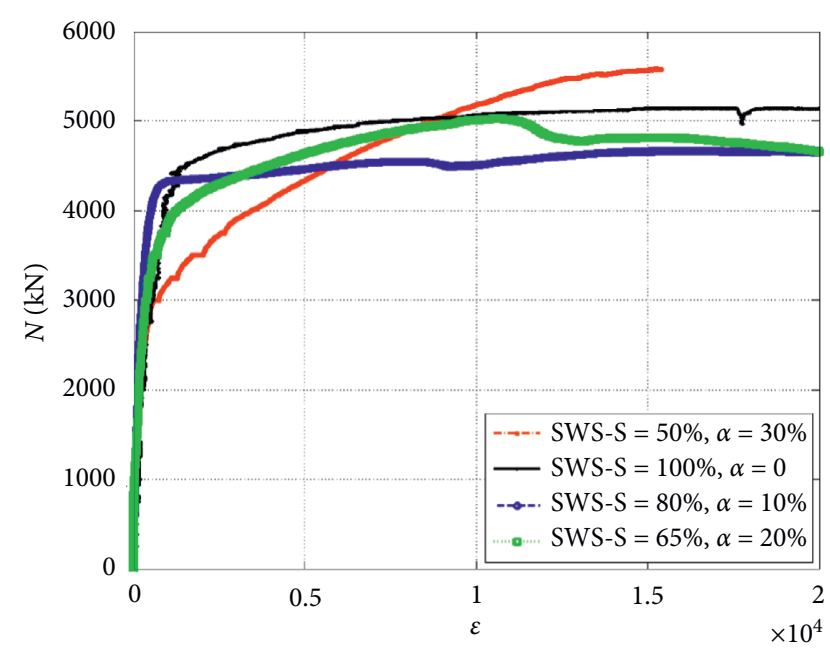

Figure 10: Axial load $(N)$ versus transverse strain $(\varepsilon T t)$.

TABLe 2: Parameters of steel tube.

\begin{tabular}{lccccccc}
\hline $\begin{array}{l}T \\
(\mathrm{~mm})\end{array}$ & $\begin{array}{c}D \\
(\mathrm{~mm})\end{array}$ & $\begin{array}{c}E_{s} \\
(\mathrm{MPa})\end{array}$ & $\mu_{s}$ & $\begin{array}{c}f_{y} \\
(\mathrm{MPa})\end{array}$ & $\begin{array}{c}f_{u} \\
(\mathrm{MPa})\end{array}$ & $\varepsilon_{y}$ & $\varepsilon_{u}$ \\
\hline 5 & 360 & $2.0 \times 10^{5}$ & 0.32 & 300 & 345 & 0.00192 & 0.179 \\
\hline
\end{tabular}

$t$ : thickness; $D$ : outer diameter; $\mu_{s}$ : Poisson's ratio.

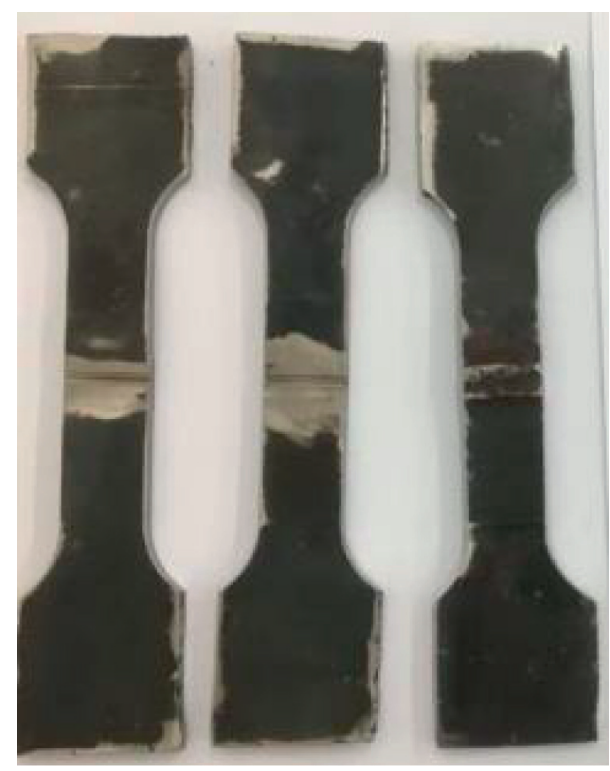

FIgURE 11: SWS specimens.

This model was used to simulate the steel material in circular CFST ribs, which can be expressed as follows:

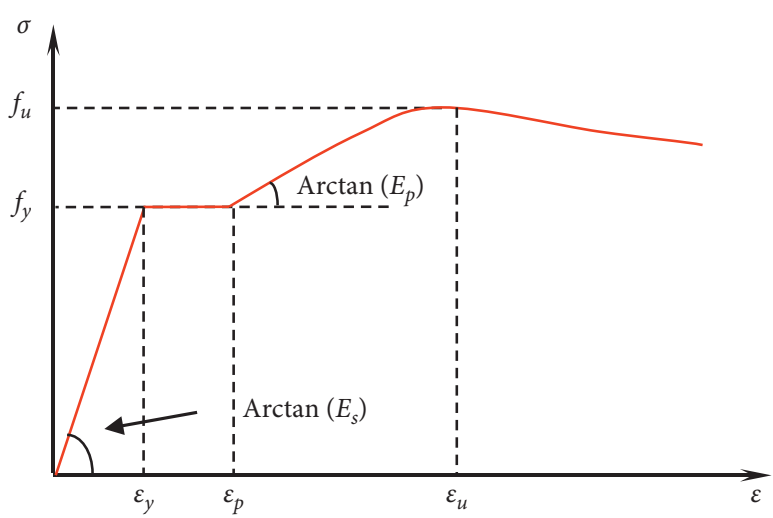

FIGURE 12: Model for steel tube properties.

$$
\sigma= \begin{cases}E_{s} \varepsilon, & 0 \leq \varepsilon<\varepsilon_{y}, \\ f_{y}, & \varepsilon_{y} \leq \varepsilon<\varepsilon_{p}, \\ f_{u}-\left(f_{u}-f_{y}\right) \cdot\left(\frac{\varepsilon_{u}-\varepsilon}{\varepsilon_{u}-\varepsilon_{p}}\right)^{p}, & \varepsilon_{p} \leq \varepsilon<\varepsilon_{u}, \\ f_{u}, & \varepsilon \geq \varepsilon_{u},\end{cases}
$$

in which $E_{s}$ is the elastic modulus at the initial point of the $\sigma-\mathcal{E}$ line; $f_{u}$ is the ultimate strength of the steel tube specimens for this case; $\varepsilon_{y}$ is the yield strain, $\varepsilon_{y}=f_{y} / E_{s} ; \varepsilon_{p}$ is the strain at the site of strain hardening; $\varepsilon_{u}$ is the ultimate strain corresponding to the ultimate strength, determined using equations (4) and (5), respectively; and $p$ is the strainhardening exponent index calculated by equation (6):

$$
\begin{aligned}
& \varepsilon_{p}= \begin{cases}15 \varepsilon_{y}, & f_{y} \leq 300 \mathrm{MPa}, \\
{\left[15-0.018\left(f_{y}-300\right)\right] \varepsilon_{y},} & 300 \mathrm{MPa}<f_{y} \leq 800 \mathrm{MPa},\end{cases} \\
& \varepsilon_{u}= \begin{cases}100 \varepsilon_{y}, & f_{y} \leq 300 \mathrm{MPa}, \\
{\left[100-0.15\left(f_{y}-300\right)\right] \varepsilon_{y},} & 300 \mathrm{MPa}<f_{y} \leq 800 \mathrm{MPa},\end{cases} \\
& P=E_{p} \cdot\left(\frac{\varepsilon_{u}-\varepsilon_{p}}{f_{u}-f_{y}}\right),
\end{aligned}
$$

where $E_{p}$ is the initial elasticity modulus at the point of strain-hardening and is taken as $0.02 E_{s}$. The following equation, proposed by Tao et al. [30], was used to distinguish $f_{u}$ from $f_{y}$ when there was no tensile failure experienced by the steel:

$$
f_{u}= \begin{cases}\left(1.6-2 \times 10^{-3}\left(f_{u}-200\right)\right) f_{y}, & 200 \mathrm{MPa} \leq f_{y} \leq 400 \mathrm{MPa}, \\ \left(1.2-3.75 \times 10^{-4}\left(f_{u}-400\right)\right) f_{y}, & 400 \mathrm{MPa}<f_{y} \leq 800 \mathrm{MPa} .\end{cases}
$$


As the steel tube was subjected to multiple direction stresses, a von Mises yield criterion $F$ was employed to express the elastic limit in ABAQUS, which is defined as

$$
F=\sqrt{3 J_{2}}=\frac{1}{\sqrt{2}} \sqrt{\left(\sigma_{1}-\sigma_{2}\right)^{2}+\left(\sigma_{2}-\sigma_{3}\right)^{2}+\left(\sigma_{3}-\sigma_{1}\right)^{2}},
$$

where $J_{2}$ is the second stress invariant of the stress deviator tensor and $\sigma_{1}, \sigma_{2}$, and $\sigma_{3}$ are principal stresses. The yield criterion of the steel tube was modeled by an associated flow rule.

When the stress points fall inside the yield surface, the steel tube behavior is linearly elastic. If the stresses of the steel tube reach the yield surface, the steel tube behavior becomes perfectly plastic. Consequently, the steel tube is assumed to fail and cannot resist any further loading.

3.1.2. Concrete. Poisson's ratio $\mu_{c}$, cylinder compressive strength $f_{c}^{\prime}$, and corresponding strain $\varepsilon_{c}^{\prime}$ of a concrete specimen with a diameter of $100 \mathrm{~mm}$ under uniaxial compressive stress are $0.21,33 \mathrm{MPa}$, and 0.0033 , respectively, in the case of this bridge.

The empirical equation (9) recommended in ACI 318-11 [31] was adopted to calculate $E_{c}$ as $2.7 \times 10^{4} \mathrm{MPa}$, where $f_{c}^{\prime}$ is in MPa:

$$
E_{c}=4700 \sqrt{f_{c}^{\prime}} .
$$

Based on test data collected from Papanikolaou and Kappos [32], the following equation was proposed to predict the ratio of $f_{b c} / f_{c}^{\prime}$ as 1.12:

$$
\frac{f_{b c}}{f_{c}^{\prime}}=1.5\left(f_{c}^{\prime}\right)^{-0.075},
$$

where $f_{b c}$ is the initial equibiaxial compressive yield stress. When core concrete has to bear a circular confining pressure, the uniaxial compressive yield strength $f_{c}^{\prime}$ and corresponding strain $\varepsilon_{c}^{\prime}$ (Figure 13) are substantially higher than those of unconfined concrete. The relations between $f_{c c}^{\prime}$ and $f_{c}^{\prime}$ and between $\varepsilon_{c c}^{\prime}$ and $\varepsilon_{c}^{\prime}$ were estimated by Mander et al. [33, 34].

According to Mander's model, Han and An [35] established an equivalent $\sigma-\varepsilon$ model to simulate the plastic behavior of the core concrete in CFSTs under compression:

$$
\begin{aligned}
& y=2 x-x^{2}, \\
& y=\left\{\begin{array}{cc}
1+q \cdot\left(x^{0.1 \xi}-1\right) & (\xi \geq 1.12) \\
\frac{x}{\beta \cdot(x-1)^{2}+x} & (\xi<1.12)
\end{array}\right\}(x>1), \\
& \sigma_{0}=\left(1+\left(-0.054 \xi^{2}+0.4 \xi\right)\left(\frac{24}{f_{c}^{\prime}}\right)^{0.45}\right) f_{c}^{\prime} \\
& \varepsilon_{0}=\varepsilon_{c c}+\left(1400+800\left(\frac{f_{c}^{\prime}}{24}-1\right)\right) \xi^{0.2}, \\
& q=\frac{\xi^{0.745}}{2+\xi}, \\
& \beta=\left(2.36 \times 10^{-5}\right)^{\left(0.25+(\xi-0.5)^{7}\right)} f_{c}^{\prime 2} \times 3.51 \times 10^{-4},
\end{aligned}
$$

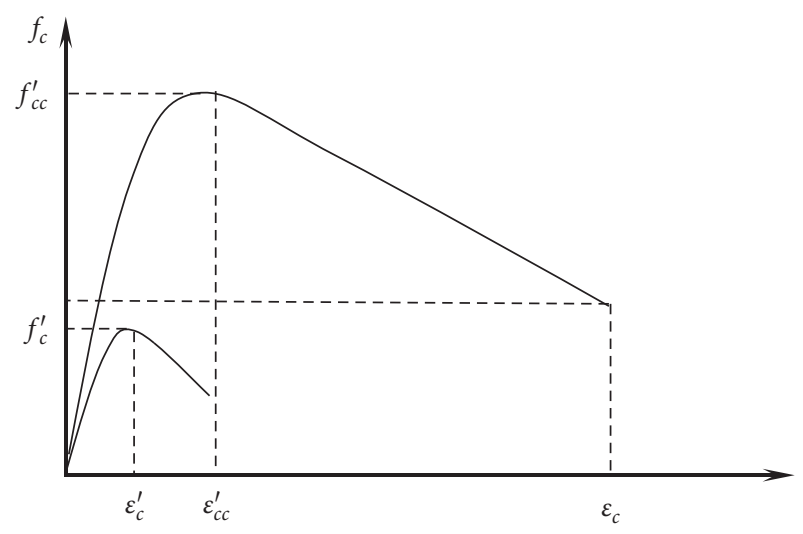

Figure 13: Stress-strain curve.

in which $x=\varepsilon / \varepsilon_{0}$ and $y=\sigma / \sigma_{0}$; the confinement factor $\xi$ is expressed as

$$
\xi=\frac{A_{s} f_{y}}{A_{c} f_{c}^{\prime}},
$$

where $A_{s}$ and $A_{c}$ are the cross-sectional areas of the SWTs and core concrete, respectively.

Because the core concrete in the CFST arch bridge rib is usually subjected to multidirectional compressive stresses, the concrete destroyed is dominated by the compressive failure surface expanding with the increasing hydrostatic pressure. Hence, a linear Drucker-Prager yield criterion $G$ (Figure 14) is used to model the yield surface of the concrete, which is expressed as

$$
G=q-p \tan \psi-d=0,
$$

where

$$
\begin{aligned}
& p=\frac{-\left(\sigma_{1}+\sigma_{2}+\sigma_{3}\right)}{3}, \\
& d=\left(1-\frac{\tan \psi}{3}\right) f_{c c}^{\prime}, \\
& q=\frac{\sqrt{3 J_{2}}}{2}\left[1+\frac{1}{K}-\left(1-\frac{1}{K}\right)\left(\frac{r}{\sqrt{3 J_{2}}}\right)^{3}\right], \\
& r=\left[\frac{9}{2}\left(S_{1}^{3}+S_{2}^{3}+S_{3}^{3}\right)\right]^{1 / 3},
\end{aligned}
$$

in which $S_{1}, S_{2}$, and $S_{3}$ are the primary stress deviators. The ratio of the second stress invariant on the tensile meridian to that on the compressive meridian $K$ is the key parameter used to determine the yield surface of the concrete plasticity stress space. According to $\mathrm{Yu}$ et al. $[36,37]$ and Tao et al. [16], equation (17) can be deduced to determine $K$ as 0.846 in this study:

$$
K=\frac{5.5}{5+2\left(f_{c}^{\prime}\right)^{0.075}}
$$

Moreover, $\beta$ represents the material parameters determined from experimental data and $\beta=20^{\circ}$ is used [19]. 


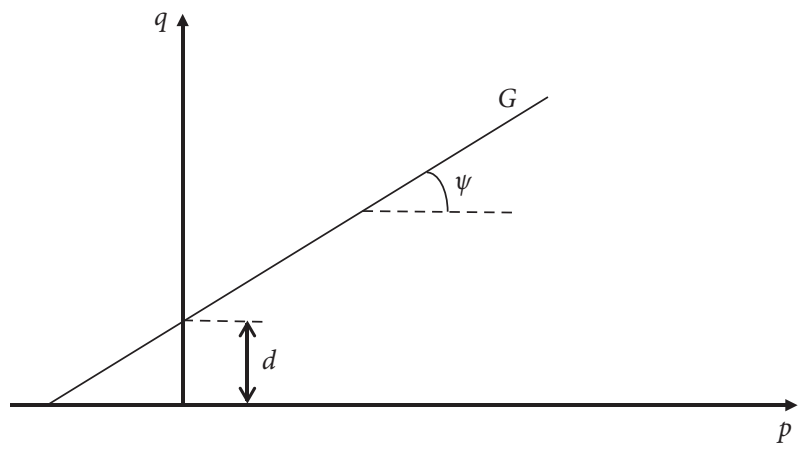

FiguRE 14: Drucker-Prager criterion.

According to the deep analysis of the CFST FEM [16], the following equation is suggested:

$$
\psi=\left\{\begin{array}{l}
56.3(1-\xi), \\
6.672 e^{7.4 / 4.64+\xi}
\end{array}\right.
$$

Therefore, $\xi=0.42$ in this CFST bridge arch rib and $\beta=33^{\circ}$.

\section{Verification of FEM}

\subsection{FEM Analysis}

4.1.1. General Conditions. Based on the software ABAQUS, a finite element model (FEM) is developed to further study the stress-strain behavior of the CFST ribs with SWS-S and air void in core concrete initial defects. The outer steel tube is modeled using four-node 3D shell elements (S4). The SWS is modeled using three-node 3D shell elements (S3), where 7 integration points are set along the thickness of two kinds of shell elements using the Simpson integration rule.

For this CFST arch bridge transverse brace, the thickness of the steel tube is only $10 \mathrm{~mm}$, but the diameter of the tube is $700 \mathrm{~mm}$, and the circumference is $2200 \mathrm{~mm}$, so the aspect ratio along the circle direction is 220 . This means that if the ideal hexahedral solid element is used to discrete the steel tube, even if the roughest element is selected along the thickness direction, 220 units need to be arranged along the circle direction, which will lead to data explosion, difficult calculation, and low accuracy of the results. If the length of circle element is lengthened, when the ratio of length to height is greater than 10 , the element stiffness matrix will be ill conditioned. In addition, the hourglass effect of the solid element will cause a large calculation error. Therefore, in order to improve the accuracy of the finite element simulation of steel tube, the shell element is used in this paper. In order to avoid the problem of compatibility of the degrees of freedom between the steel tube shell and the concrete solid elements, this FEM established a column coordinate system for the steel tube in the postprocessing process.

The core concrete is modeled using eight-node 3D solid elements (C3D8). The steel tube is meshed with the free meshing technique, and the concrete core is meshed with the structural meshing technique in ABAQUS to obtain an optimized distributing mesh style.
The defect elements are based on the abnormal area detected by CFST ultrasound. The Python random program is adopted to read the elements in this area of the FEM and randomly extract $10 \%, 20 \%$, and $30 \%$ elements, within $200 \mathrm{~mm}$ of the model center, respectively, as pores according to the normal distribution of space, so as to realize the sampling level of different air void defects.

Enforced displacement at the top reference point of a rib was applied to realize the eccentric axial loading boundary condition. As the bridge arch rib is a compression member with small eccentricity, the eccentricity was determined as $D / 6$, according to the load combination. The CFST ends were constrained by an analytical rigid body. The rigid plate of the CFST ends was simulated by coupling the surface node DoFs on the reference points, which were located at the center of the upper and lower surfaces. All DoFs of one point were fixed, while a displacement of $L / 15$ was applied to the other point, where $L$ is the effective rib length.

A comparison between the experimental data of Gunawardena et al. [3], Liao et al. [24, 25], and the FEM analysis results was carried out to verify the FEM rationality of this bridge rib. It can be observed that the ribs with decreased SWS strength or a single defect of air void generally exhibited outward local buckling for the steel tubes at the SWS defect, while the overall lateral deflection at midheight was also observed. The predicted distorted modes scientifically demonstrated reasonable agreement with the experienced phenomenon despite little differences in terms of the local buckling position. The predicted eccentric axial load $N$ versus axial strain $\varepsilon$ curves were compared with the typical measured curves. The predicted ultimate limit states were compared with those obtained from tests. In brief, it was obtained in identical agreement between the predicted FEM and experimental data.

For a CFST rib with air void defect, it appears that the air void rate is a decisive factor affecting the rib bearing capacity. There has been no SWS-S defect research thus far, and the SWSs studied by Gunawardena and Aslani [2] and Gunawardena et al. [3] were standard welds that met the design requirements and had no defects. However, the arch rib element SWSs of this bridge is defective. Therefore, the composite defects of the CFST columns with a decreased SWS strength and air void are analyzed in the following sections.

4.1.2. SWTs-Core Concrete Interface. In the past twenty years, a normal direction hard contact interaction pressure model and a tangential direction friction Coulomb model for the surface between the SWTs and core concrete have been widely used in the FEM of CFST columns, by ABAQUS software. These types of models were also used in this study [12]. For the CFST with a circumferential gap or not, the shear stress $\tau_{\text {crit }}$ on the interface between the core concrete and SWT will continue to increase with an increase in the normal contact interaction until it exceeds the surface bond strength $\tau_{\text {bond }}$. Thereafter, a relative slip is constructed and the shear stress is taken as a constant value. The $\tau_{\text {crit }}$ value is expressed as follows: 


$$
\tau_{\text {crit }}=u \cdot p \geq \tau_{\text {bond }}
$$

where $u$ is the friction coefficient, which is taken as 0.6 in this case [38], and

$$
\tau_{\text {bond }}=2.314-0.0195 \cdot \frac{D}{t} \text {. }
$$

The surface of the core concrete in a CFST rib with a circumferential gap is not in direct contact with the inner surface of the SWTs during the initial bearing stage. Therefore, both the tangential shear stress and normal contact pressure stress are initially taken as zero in this FEM. Then, after contact occurs, the tangential frictional stress $\tau_{\text {fric }}$ relies on the value of the normal pressure stress $p_{n}$ and can be expressed as

$$
\tau_{\text {fric }}=u \cdot p_{n}
$$

\subsection{Analysis of CFST Rib with or without SWS-S Defect}

4.2.1. N-E Curves of CFST Rib with or without SWS-S Defect. The SWS strength (SWS-S) was 50\%, 65\%, 80\%, and 100\%, respectively, of an ideal strength as strong as the parent material. The screw-pitch was $0.8 \mathrm{~m}$, and the length $L$ was $1500 \mathrm{~mm}$.

It can be observed from Figure 15 that the $N$ versus $\varepsilon$ curves of the CFST rib almost coincided with one another under different SWS-S defect conditions. Only at strain softening scope, the weld strength has a little influence on the bearing capacity. Therefore, it can be concluded that the strength reduction of the SWS single defect had almost no effect on the CFST bearing capacity when the internal concrete had no defects. This is certificated by the observations of previous experiences in Gunawardena and Aslani [2] and Gunawardena et al. [3].

4.2.2. Typical Destroyed Modes with or without SWS-S Defect. The typical SWTs and the core concrete column failure modes in the CFST rib are compared in Figures 16 and 17.

It illustrates that the strength of the outer SWT of the CFST decreased at the weld seam. Moreover, a strong capability of confining the core concrete was demonstrated, which fully provided support for the outer steel tube and prevented local bucking if there were no defects in the core concrete. This ensured the coinciding performance of the steel tube and concrete working together.

Figure 17 presents the Mises stresses of the core concrete of the CFST under different SWS-S. It was found that the stresses (Mises) carried by the SWT or core concrete and the CFST deformation were approximately the same for the ribs with and without an SWS-S defect. This occurred despite the SWS-S causing a strength loss of the SWTs belt of $20 \%$ to $50 \%$ in this example owing to the weld seam defects.

Therefore, it can be realized that the CFST rib strength reduction with an SWS-S defect was not obvious when the core concrete was fully filled. It can also be determined that the strength of the SWS with defects was decreased at the weld area.

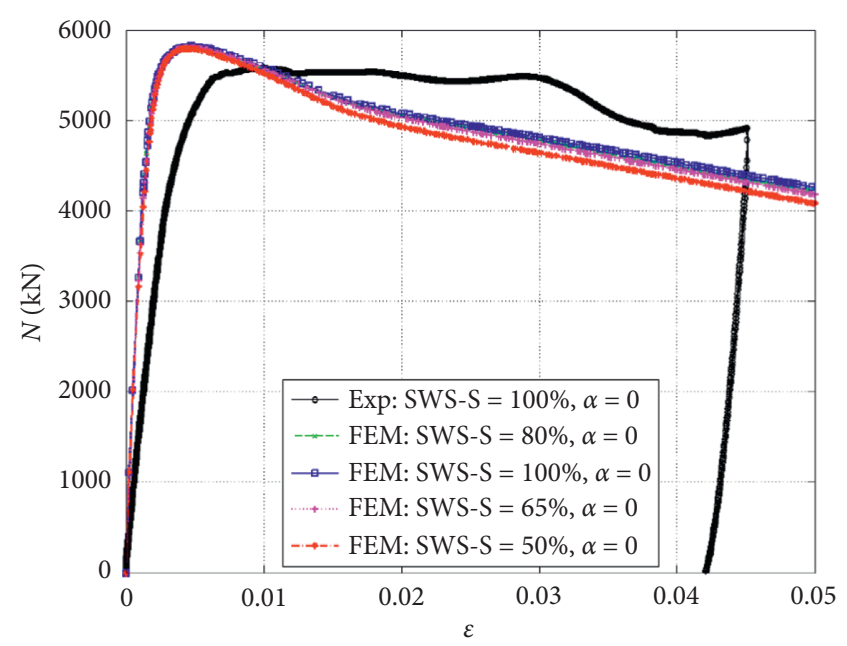

Figure 15: Comparison of $N$ versus $\varepsilon$ relations.

\subsubsection{Analysis of CFST Arch Rib with Air Void Defect}

(1) N-E Curves with Air Void Defect. Figure 18 compares the $N-\varepsilon$ curves of the CFST rib with different air void rates ( $\alpha=10 \%, 20 \%$, and 30\%) or without. It can be observed from Figure 18 that the CFST exhibited typical strain-softening characteristics when there were air voids or not, which is consistent with the results in Gunawardena and Aslani [2] and Gunawardena et al. [3].

The strain-softening and yield occurred when air void existed in the CFST rib, which is consistent with the results of Liao et al. [24, 25], Han et al. [27], and Liu et al. [28]. To analyze the influence of the air void rate on the CFST bearing capacity more clearly, the $N-\varepsilon$ curves under the conditions of each air void rate are presented separately in Figure 18. There is one yield point at the different $\alpha$ corresponding to the $N-\varepsilon$ curves when the peak load was attained, which refer to the strain-softening. It can be observed from Figure 18 that the $N$ of the rib with the air voids decreased suddenly after the peak load (note that all $N-\varepsilon$ curves exhibited smooth shapes). When there is no air void defect, the peak value of $N-\varepsilon$ curves reaches $5800 \mathrm{kN}$; as $\alpha=10 \%$, the peak value of $N-\varepsilon$ curves drops to $5735 \mathrm{kN}$; as $\alpha=20 \%$, the peak value of $N-\varepsilon$ curves drops to $5315 \mathrm{kN}$; while $\alpha=30 \%$, the peak value of $N-\varepsilon$ curve drops to $4840 \mathrm{kN}$, which is $16.6 \%$ lower than the sound condition.

(2) Typical Destroyed Modes with Air Void Defect. The typical destroyed modes of the CFST rib are compared in Figure 19, and the elephant foot-shaped buckling deformation is amplified two times to illustrate the deformed shapes of the columns more clearly. These were found near the middle of the CFST stub column. It is worth noting that, for the CFST with $\alpha=10 \%$, the wall of the tube is almost smooth with no local buckling. For the CFST with $\alpha=20 \%$, only a little drum buckling deformation occurred, while for the CFST with $\alpha=30 \%$, there were serried drum buckling deformations, indicating that a larger air void resulted in a larger space for local buckling deformation of the steel tube. 


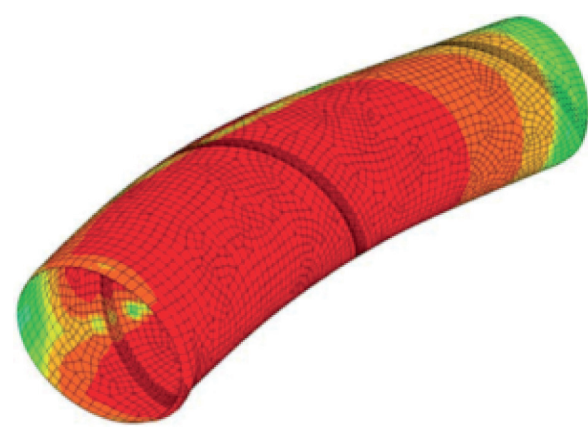

(a)

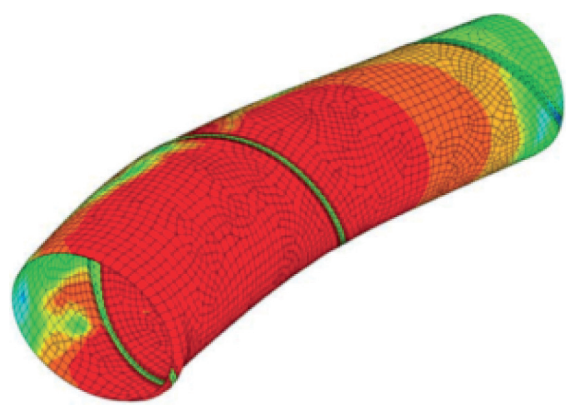

(c)

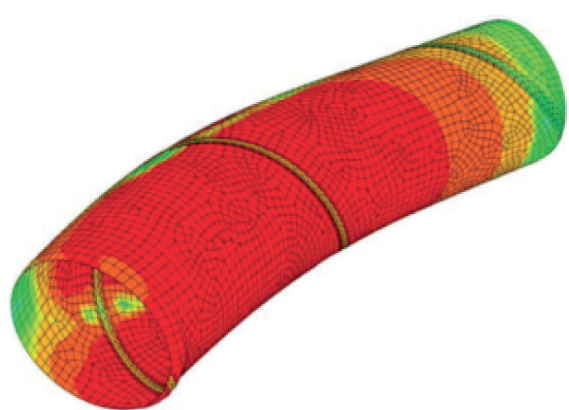

(b)

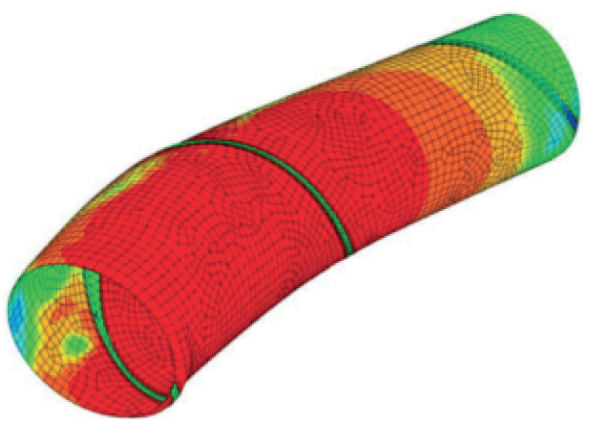

(d)

Figure 16: Tube Mises stresses in CFST with different SWS-S: (a) SWS-S: 100\%; (b) SWS-S: 80\%; (c) SWS-S: 65\%; (d) SWS-S: 50\%.

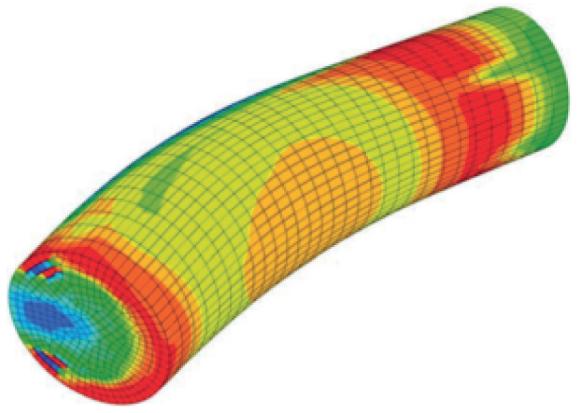

(a)

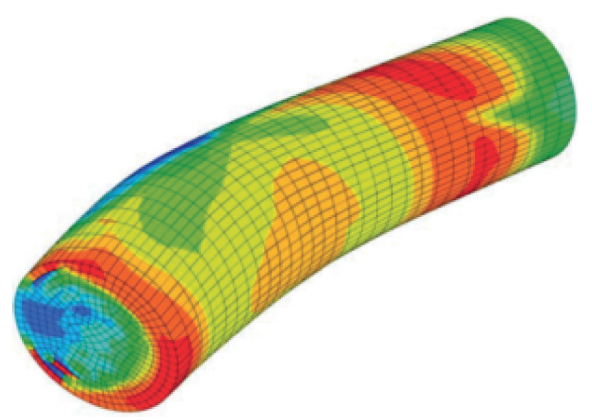

(c)

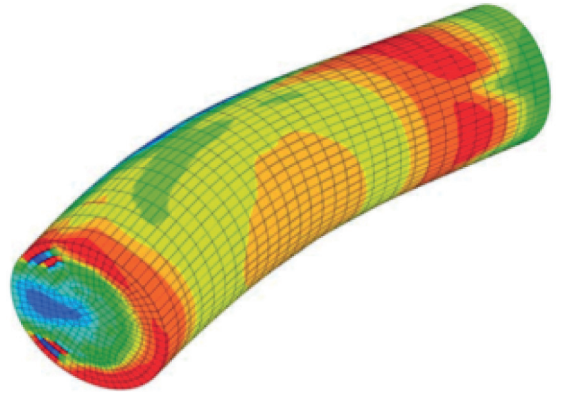

(b)

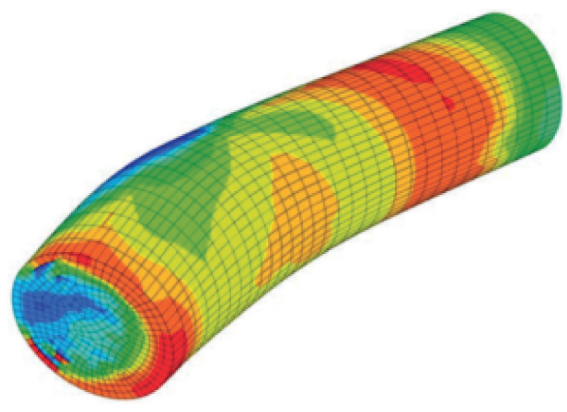

(d)

Figure 17: Concrete Mises stresses in CFST with different SWS-S: (a) SWS-S: 100\%; (b) SWS-S: 80\%; (c) SWS-S: 65\%; (d) SWS-S: 50\%.

The deformed shapes of the concrete core with different air void rates at middle $0.2 \mathrm{~m}$ region are presented in Figure 20. It can be observed that the concrete exhibited different bending deformation modes under different air void rates.
When the air void rate was low, the concrete bending deformation was closer to that under a complete constraint, as indicated in Figure 17.

With the increase in the air void rate, the bending deformation and stress became increasingly concentrated at 


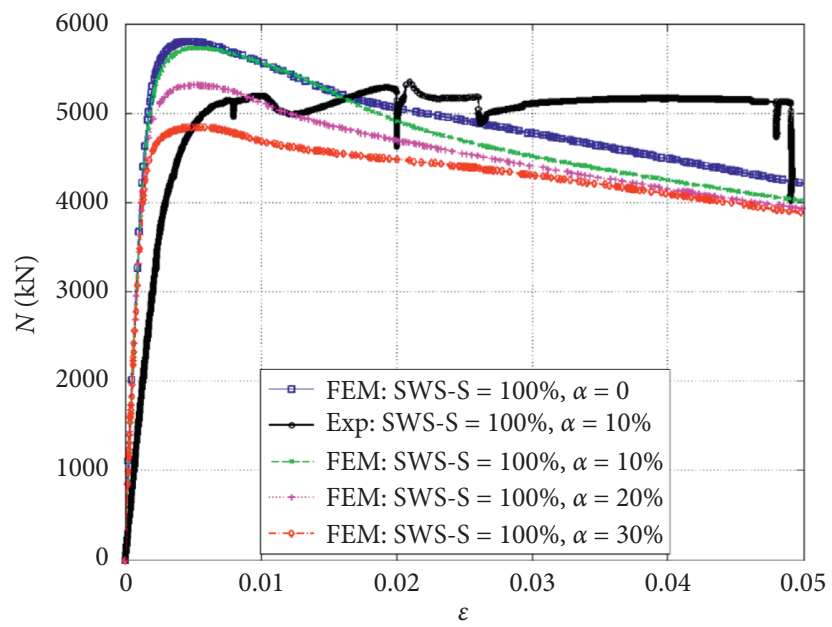

Figure 18: Comparison of $N-\varepsilon$ relations.

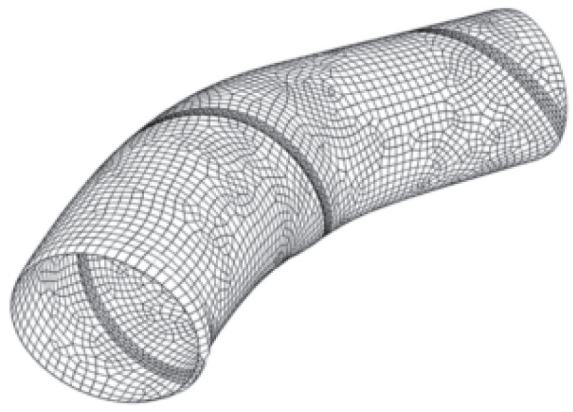

(a)

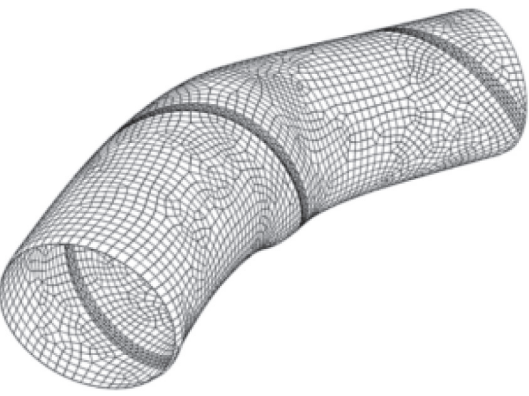

(b)

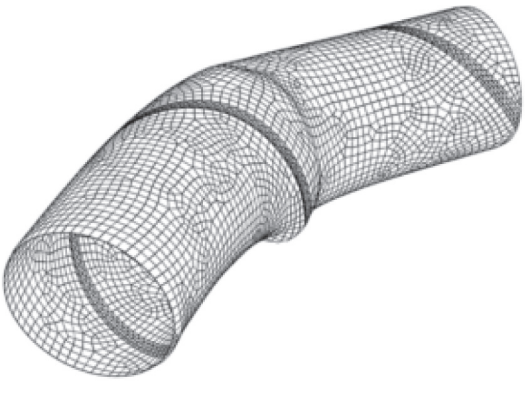

(c)

Figure 19: Destroyed modes of CFST with different $\alpha$ : (a) $\alpha=10 \%$; (b) $\alpha=20 \%$; (c) $\alpha=30 \%$.

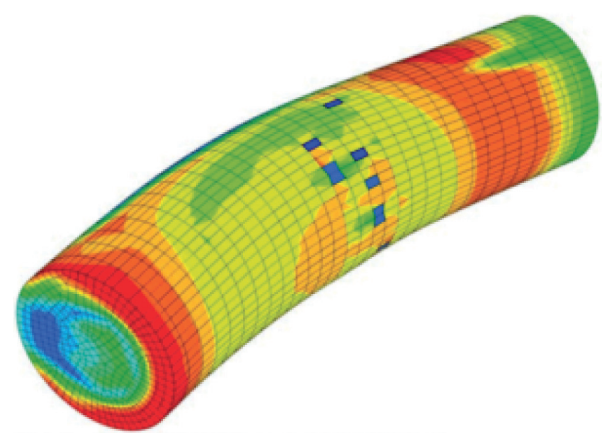

(a)

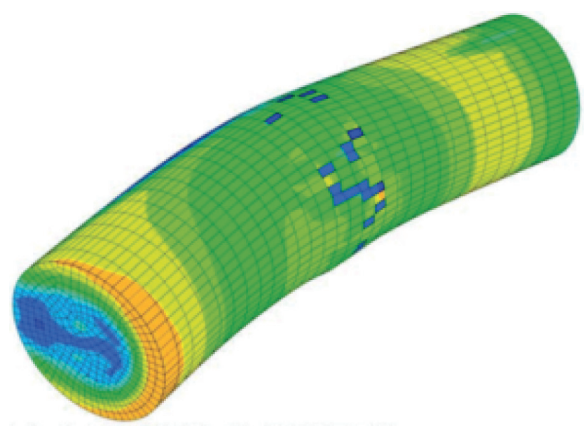

(b)

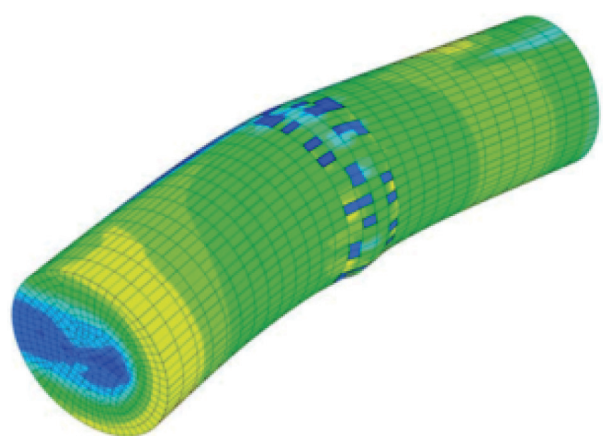

(c)

Figure 20: Concrete Mises stresses in CFST with different air void rates: (a) $\alpha=10 \%$; (b) $\alpha=20 \%$; (c) $\alpha=30 \%$. 
the middle region, and the CFST exhibited the situation of local fracture and the brittle failure stage. It can be discovered that, with the air void rate increasing, the greatest cross section deformation of the concrete occurred at the middle. Then, after the air void in concrete was compacted, the cross-section deformation of the concrete at the root was confined by the SWTs again. As a result, the cracked location of the concrete tended to move towards the rib midheight. Failure of the concrete was observed at the sections where the SWTs local buckling occurred, as indicated in Figure 16.

\subsubsection{Analysis of CFST Arch Rib with SWS-S and Air Void Composite Defects}

(1) $N-\varepsilon$ Curves with Composite Defects. Figure 21 compares the $\mathrm{N}-\varepsilon$ curves of the CFSTs with a decrease in SWS-S (SWS$S=100 \%, 80 \%, 65 \%$, and $50 \%)$ and air void rate $(\alpha=10 \%$, $20 \%$, and $30 \%$ ) composite defects in three dimensions.

It can be observed from Figure 21 that all of the CFST ribs exhibited typical smooth strain-softening characteristics when SWS-S existed without air void defects. This is quite similar to the results presented in Figure 15. However, under the composite effects of different air void rates, the $N-\varepsilon$ curves of each component exhibited different variation rules. With the increasing air void rate, the number and length of the yield steps on the $N-\varepsilon$ loss curve increased gradually, indicating that the $N-\varepsilon$ loss curve of the air void rate on the CFST increased gradually after the peak strength. This was mainly owing to the weakened bearing capacity of the random air void defects in the concrete column core, which reduced the composite bearing capacity of the CFST.

(2) Typical Destroyed Modes with Composite Defects. The typical failure modes of the CFST ribs are compared in Figures 22 and 23 under different SWS-S and air void composite defects. These were found near the middle of the CFST ribs as in Figure 22. It is worth noting that, for the CFST with $\alpha=10 \%$ under different SWS-S, no bulging deformation occurred, while for the CFST with $\alpha=20 \%$, there was a slight one; when $\alpha=30 \%$, there was a serious one, the same as in Figure 19.

As illustrated in Figure 22, when the air void rate $\alpha$ was 10\% to $30 \%$ of the core concrete and SWS-S decreased from $80 \%$ to $50 \%$, the bulging deformation was more seriously on the composition side and transferred to the folded failure mode, indicating that the composite defects were the source of the CFST bending failure. The SWS-S had less impact on the tube.

Figure 23 illustrates that when the air void rate $\alpha$ increased from $10 \%$ to $30 \%$ of the ideal volume of the concrete core, with SWS-S decreased from $80 \%$ to $50 \%$, the influence of air void was more and more serious. Due to the increase in $\alpha$, the concrete in the peripheral annulus of air void distribution could not form a continuous force body and quit working condition. This makes the stress concentrated inside the concrete core column, which is equivalent to the reduction of the section of the concrete core column, while the constraint of the outer steel tube on the concrete core column is further weakened. The stress and deformation of the core concrete column were basically consistent with the results in Figure 20.
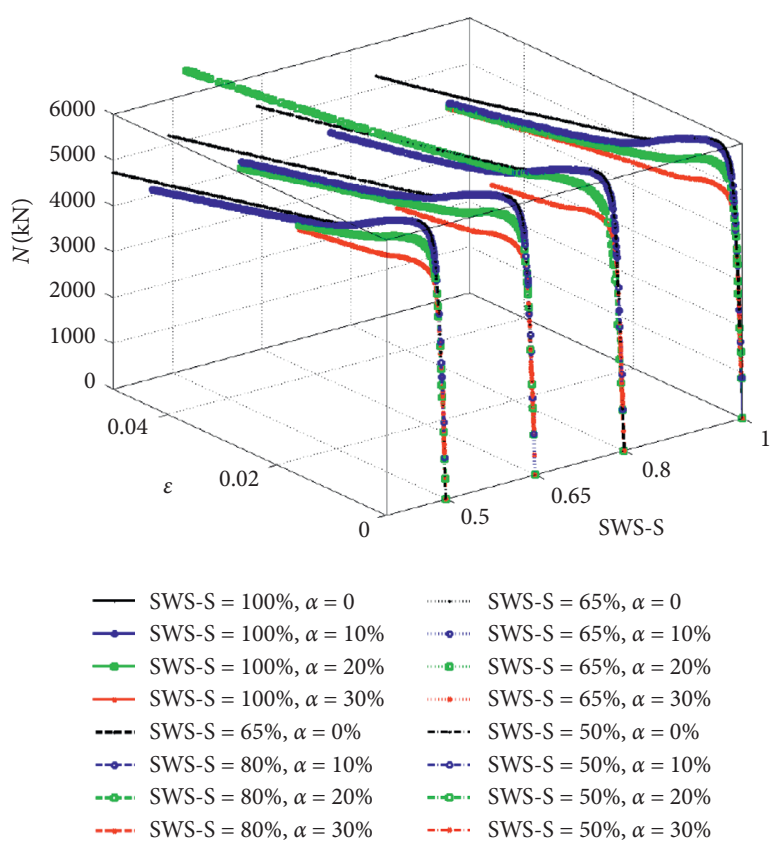

FIgURE 21: $N-\mathcal{E}$-curves under composite defects.

4.2.5. Composite Strength Index. For quantitative evaluation of the influence of the SWS-S and air void composite defects on the CFST bearing capacity, a strength index SI is defined by equation (2). The SI values are nearly equal to 1 , when single defect of SWS-S decreased from $80 \%$ to $50 \%$. However, when single defect of $\alpha$ increased further from $10 \%$ to $30 \%$, SI values decreased rapidly to 0.842 . This pattern of the rapid SI decline also occurred when the air void rate was from $10 \%$ to $30 \%$, the SWS-S value decreased from $80 \%$ to $50 \%$, and the SI value decreased from 1 to 0.834 . The SI value with the SWS-S and $\alpha$ composite defects matrix was listed as follows:

$$
\text { SI }=\alpha\left[\begin{array}{c}
0 \\
0.1 \\
0.2 \\
0.3
\end{array}\right]\left[\begin{array}{cccc}
1 & 0.998 & 0.996 & 0.995 \\
0.989 & 0.992 & 0.991 & 0.990 \\
0.916 & 0.925 & 0.923 & 0.923 \\
0.842 & 0.841 & 0.840 & 0.834
\end{array}\right] .
$$

Therefore, a multiple linear regression method was adopted to establish the relationship between SI and SWS-S and $\alpha$, as follows (illustrated in Figure 24):

$$
\mathrm{SI}=1-a\left(e^{\left(b \alpha^{1.2}+c S W S-S^{0.8}\right)}-1\right) .
$$

The coefficients (with 95\% confidence bounds) were as follows: $a=0.223, b=2.038$, and $c=7.143$. The goodness of fit was determined as follows: SSE: $0.04183, R$-square: 0.98 , adjusted $R$-square: 0.99 , and RMSE: 0.026 . It can be determined from equation (24) that the significance of SWS-S on SI was almost equal with that of $\alpha$. Furthermore, the SWS-S and air void had nearly the same significant effect on the destroyed mode, bearing capacity, and corresponding deformation of the CFST ribs. 


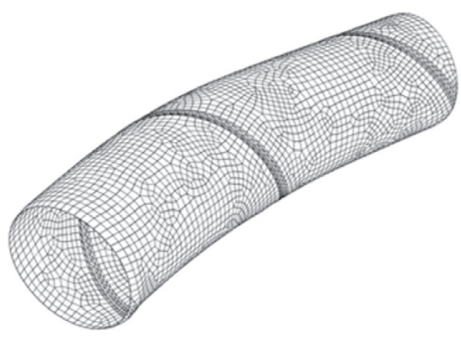

(a)

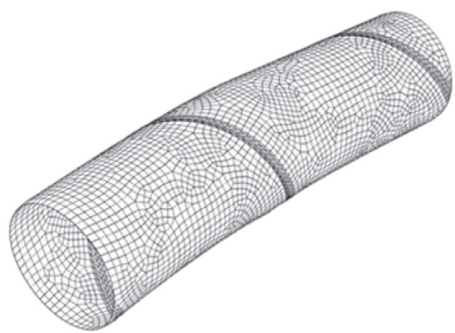

(d)

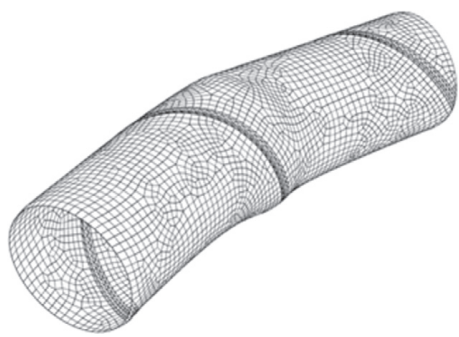

(g)

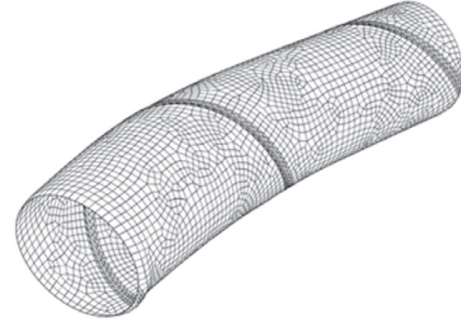

(b)

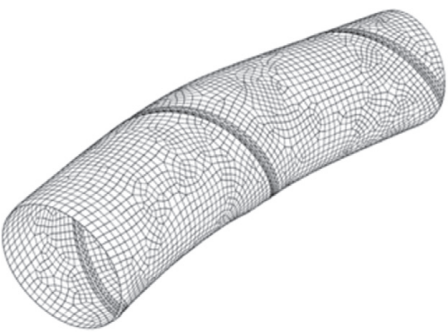

(e)

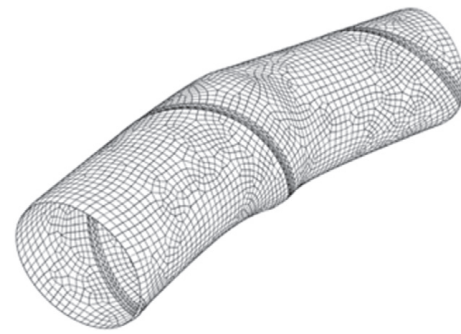

(h)

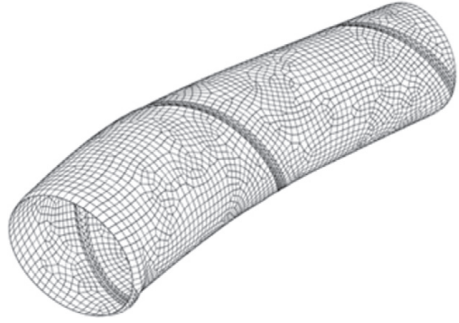

(c)

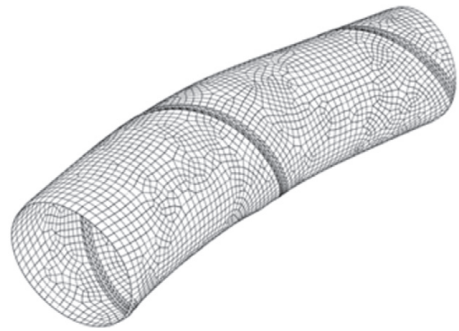

(f)

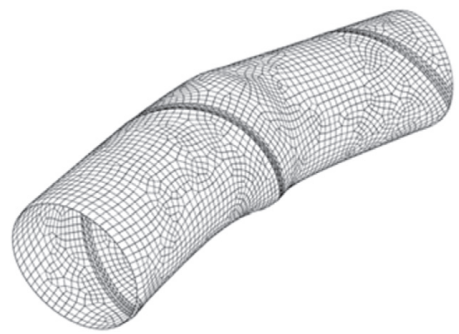

(i)

FiguRE 22: Destroyed modes of CFST under different composite defects: (a) SWS-S $=80 \%$ and $\alpha=10 \%$; (b) SWS-S $=65 \%$ and $\alpha=10 \%$; (c) SWS-S $=50 \%$ and $\alpha=10 \%$; (d) SWS-S $=80 \%$ and $\alpha=20 \%$; (e) SWS-S $=65 \%$ and $\alpha=20 \%$; (f) SWS-S $=50 \%$ and $\alpha=20 \%$; (g) SWS-S $=50 \%$ and $\alpha=30 \%$; (h) SWS-S $=50 \%$ and $\alpha=30 \%$; (i) SWS-S $=50 \%$ and $\alpha=30 \%$.

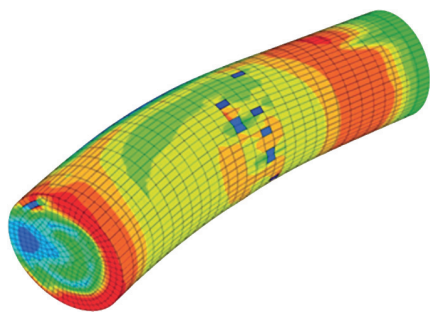

(a)

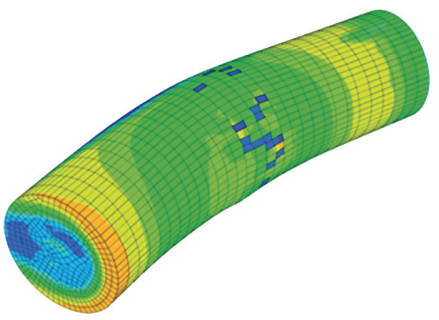

(d)

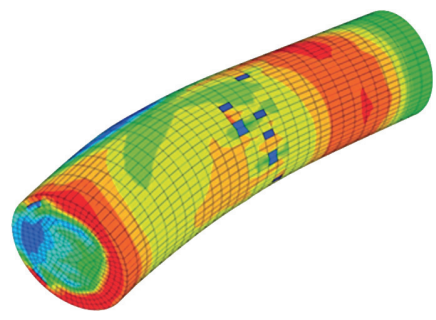

(b)

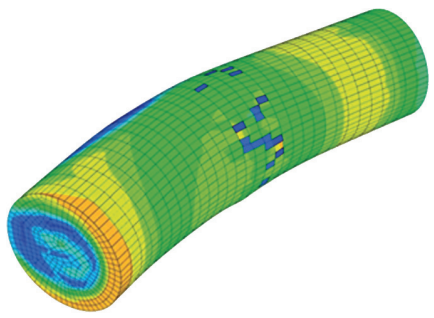

(e)

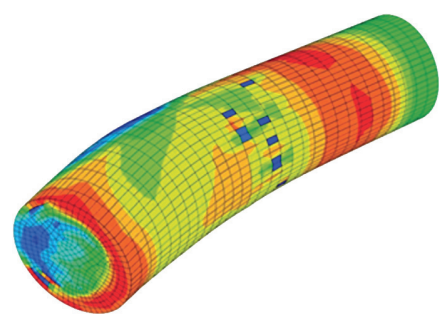

(c)

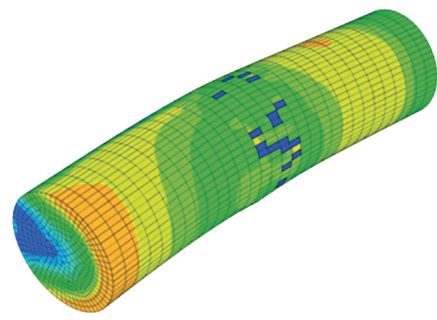

(f)

Figure 23: Continued. 


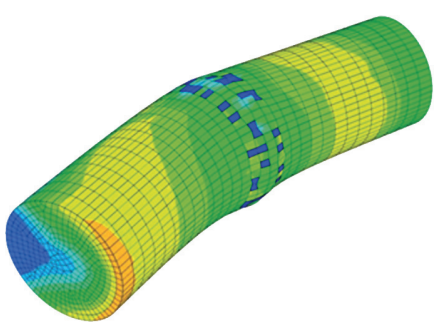

(g)

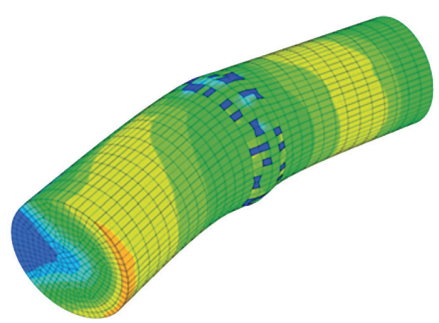

(h)

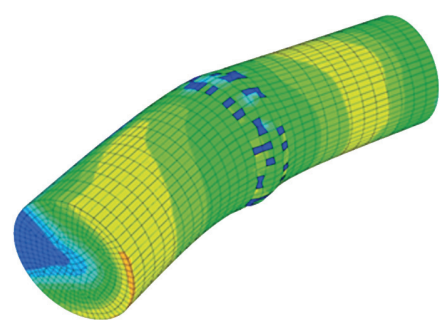

(i)

FIGURE 23: Concrete Mises stresses under composite defects: (a) SWS-S $=80 \%$ and $\alpha=10 \%$; (b) SWS-S $=65 \%$ and $\alpha=10$; (c) SWS-S $=50 \%$ and $\alpha=10$; (d) SWS-S $=80 \%$ and $\alpha=20$; (e) SWS-S $=65 \%$ and $\alpha=20$; (f) SWS-S $=50 \%$ and $\alpha=20$; (g) SWS-S $=80 \%$ and $\alpha=20$; (h) SWS$\mathrm{S}=65 \%$ and $\alpha=30$; (i) SWS-S $=50 \%$ and $\alpha=30$.

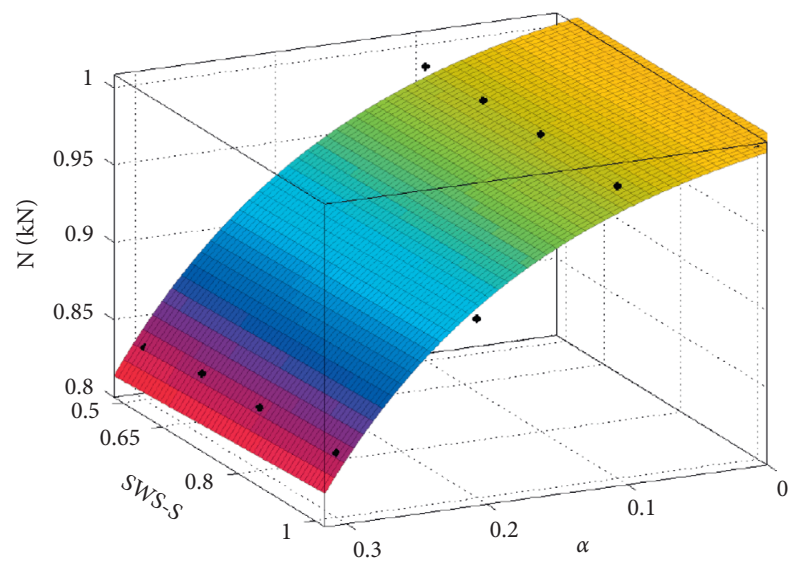

FIGURE 24: Influence of SWS-S and $\alpha$ on SI.

Through the calculation (24) and Figure 24, $\alpha$ and SWS-S values calibrated by ultrasonic array or borehole coring are calculated quantitatively, the influence of the bearing capacity and strength index SI of CFST is analyzed, and the influencing factors of the composite defects are visualized.

\section{Conclusions}

In this study, ultrasonic scanning experimental field data of the Chang-Qing Hun River Bridge were collected and used to develop a group of scale model tests with composite defects and FEM for simulating the CFST arch bridge rib under eccentric axial compression. This calculated model was compared with existing experiments and FEM developed by Liao et al. [25], Han et al. [27], and Tao et al. [16], in terms of prediction accuracy. The following conclusions can be drawn based on this study:

(1) Using ultrasonic scanning, the actual defects of the concrete core column in the original CFST arch bridge were obtained. The ratio of the interface gap area to the total tube area is approximately $3.6 \%$ to $30.5 \%$, and the signal anomaly area depth is approximately to the core.

(2) A group of experiments and FEMs were developed in this study for the CFST truss rib of the arch bridge, and the strain-hardening/softening and yielding laws of the peak-post curves of the CFST for steel tube local buckling coupled with different SWS-S were obtained.

(3) Through the analysis of experiments and FEMs results, it was found that SWS-S defect has little effect on CFST bearing capacity.

(4) The effect of SWS-S and air void in concrete core composite defects on CFST columns was analyzed through experiments and FEMs, and the results perfectly estimate the significant effect of random air void of concrete core on the ultimate strengths of circular truss element ribs for the CFST during long service in harsh conditions in the arch bridge practice.

(5) A new strength index, SI, of the CFST under air void defect was defined on the group of FEM and experiments results. The predictions using the new index were compared with the test data collected, which indicated that the new index is more accurate and versatile in calculating CFST ribs bearing capacity with the SWS-S and air void defect in concrete core.

(6) The new index SI expression quantitatively illustrates that $\alpha$ has a significant impact on the CFST bearing capacity, and therefore, reducing the air void in concrete core is a key index for ensuring the CFST arch bridge bearing capacity.

\section{Data Availability}

All data, models, and code included in this study are available upon request by contact with the corresponding author.

\section{Conflicts of Interest}

The authors declare that there are no conflicts of interest.

\section{Acknowledgments}

This research was supported by the National Key Research and Development Program of China (no. 2018YFD1100404), Plan of Liaoning Province to revitalize Liaoning talents (no. XLYC1907121), Province Natural Science Foundation of Liaoning, China (no. 20180550442), 
and Scientific Research Project of Liaoning Provincial Department of Education (no. lnjc201904).

\section{References}

[1] J. Zheng and J. Wang, "Concrete-filled steel tube arch bridges in China," Engineering, vol. 4, no. 1, pp. 143-155, 2018.

[2] Y. Gunawardena and F. Aslani, "Behaviour and design of concrete-filled mild-steel spiral welded tube short columns under eccentric axial compression loading," Journal of Constructional Steel Research, vol. 151, pp. 146-173, 2018.

[3] Y. Gunawardena, F. Aslani, J. Li, and H. Hao, "In situ data analysis for condition assessment of an existing prestressed concrete bridge," Journal of Aerospace Engineering, vol. 31, no. 6, Article ID 04018106, 2018.

[4] R. Sovannsathya, M. Ouchi, N. Puthipad, and A. Attachaiyawuth, "Improving the stability of entrained air in self-compacting concrete by optimizing the mix viscosity and air entraining agent dosage," Construction and Building Materials, vol. 148, pp. 531-537, 2017.

[5] M. Diaferio, A. Fraddosio, M. D. Piccioni, A. Castellano, L. Mangialardi, and L. Soria, "Some issues in the structural health monitoring of a railway viaduct by ground based radar interferometry," in Proceedings of the 2017 IEEE Workshop on Environmental, Energy, and Structural Monitoring Systems (EESMS), pp. 24-25, Milan, Italy, July 2017.

[6] A. Castellano, A. Fraddosio, and M. D. Piccioni, "Ultrasonic goniometric immersion tests for the characterization of fatigue post-LVI damage induced anisotropy superimposed to the constitutive anisotropy of polymer composites," Composites Part B: Engineering, vol. 116, no. 1, pp. 122-136, 2017.

[7] A. Castellano, A. Fraddosio, and M. D. Piccioni, "Quantitative analysis of QSI and LVI damage in GFRP unidirectional composite laminates by a new ultrasonic approach," Composites Part B: Engineering, vol. 151, no. 15, pp. 106-117, 2018.

[8] W. Dong, Z. Wu, X. Zhou, and Y. Tan, "Experimental studies on void detection in concrete-filled steel tubes using ultrasound," Construction and Building Materials, vol. 128, pp. 154-162, 2016.

[9] H. Liu, H. Xia, M. Zhuang et al., "Reverse time migration of acoustic waves for imaging based defects detection for concrete and CFST structures," Mechanical Systems and Signal Processing, vol. 117, pp. 210-220, 2019.

[10] F.-X. Ye, X.-X. Zha, H.-X. Wang et al., "The application of a HHT based ultrasonic detecting method in quality assessment of CFST," Advanced Steel Construction, vol. 7, no. 2, pp. 182-191, 2011.

[11] S. Yan, B. Zhang, G. Song, and J. Lin, "PZT-based ultrasonic guided wave frequency dispersion characteristics of tubular structures for different interfacial boundaries," Sensors, vol. 18, no. 12, pp. 4111-4133, 2018.

[12] L.-H. Han, G.-H. Yao, and Z. Tao, "Performance of concretefilled thin-walled steel tubes under pure torsion," Thin-Walled Structures, vol. 45, no. 1, pp. 24-36, 2007.

[13] C. N. Srinivasan and S. P. Schneider, "Axially loaded concretefilled steel tubes,” Journal of Structural Engineering, vol. 125, no. 10 , pp. $25-38,1999$.

[14] H.-T. Hu, C.-S. Huang, M.-H. Wu, and Y.-M. Wu, "Nonlinear analysis of axially loaded concrete-filled tube columns with confinement effect," Journal of Structural Engineering, vol. 12, no. 10, pp. 1322-1329, 2003.

[15] E. Ellobody and B. Young, "Nonlinear analysis of concretefilled steel SHS and RHS columns," Thin-Walled Structures, vol. 44, no. 8, pp. 919-930, 2006.
[16] Z. Tao, B. Uy, F.-Y. Liao, and L.-H. Han, "Nonlinear analysis of concrete-filled square stainless steel stub columns under axial compression," Journal of Constructional Steel Research, vol. 67, no. 11, pp. 1719-1732, 2011.

[17] Z. Tao, B. Uy, L.-H. Han, and Z.-B. Wang, "Analysis and design of concrete-filled stiffened thin-walled steel tubular columns under axial compression," Thin-Walled Structures, vol. 47, no. 12, pp. 1544-1556, 2009.

[18] M. F. Hao, "Numerical modelling of concrete-filled lean duplex slender stainless steel tubular stub columns," Journal of Constructional Steel Research, vol. 66, no. 8-9, pp. 1057-1068, 2010.

[19] E. Ellobody and B. Young, "Design and behaviour of concretefilled cold-formed stainless steel tube columns," Engineering Structures, vol. 28, no. 5, pp. 716-728, 2006.

[20] X. Dai and D. Lam, "Numerical modelling of the axial compressive behaviour of short concrete-filled elliptical steel columns," Journal of Constructional Steel Research, vol. 66, no. 7, pp. 931-942, 2010.

[21] H. Huang, L.-H. Han, Z. Tao, and X.-L. Zhao, "Analytical behaviour of concrete-filled double skin steel tubular (CFDST) stub columns," Journal of Constructional Steel Research, vol. 66, no. 4, pp. 542-555, 2010.

[22] H.-T. Hu and F.-C. Su, "Nonlinear analysis of short concretefilled double skin tube columns subjected to axial compressive forces," Marine Structures, vol. 24, no. 4, pp. 319-337, 2011.

[23] B. Jaishi and W.-X. Ren, "Structural finite element model updating using ambient vibration test results," Journal of Structural Engineering, vol. 131, no. 4, pp. 617-628, 2005.

[24] F.-Y. Liao, L.-H. Han, and S.-H. He, "Behavior of CFST short column and beam with initial concrete imperfection: Experiments," Journal of Constructional Steel Research, vol. 67, no. 12, pp. 1922-1935, 2011.

[25] F.-Y. Liao, L.-H. Han, and Z. Tao, "Behaviour of CFST stub columns with initial concrete imperfection: analysis and calculations," Thin-Walled Structures, vol. 70, pp. 57-69, 2013.

[26] L.-H. Han, C.-C. Hou, and Q.-L. Wang, "Behavior of circular CFST stub columns under sustained load and chloride corrosion," Journal of Constructional Steel Research, vol. 103, pp. 23-36, 2014.

[27] L.-H. Han, Y. Ye, and F.-Y. Liao, "Effects of core concrete initial imperfection on performance of eccentrically loaded CFST columns," Journal of Structural Engineering, vol. 142, no. 12, Article ID 04016132, 2016.

[28] X.-P. Liu, Z. Sun, S. Tang, H.-Y. Huang, and A.-R. Liu, “A new calculation method for axial load capacity of separated concrete-filled steel tubes based on limit equilibrium theory," Journal of Central South University, vol. 20, no. 6, pp. 1750$1758,2013$.

[29] Y.-H. Huang, A.-R. Liu, J.-Y. Fu, and Y.-L. Pi, "Experimental investigation of the flexural behavior of CFST trusses with interfacial imperfection," Journal of Constructional Steel Research, vol. 137, pp. 52-65, 2017.

[30] Z. Tao, Z.-B. Wang, and Q. Yu, "Finite element modelling of concrete-filled steel stub columns under axial compression," Journal of Constructional Steel Research, vol. 89, pp. 121-131, 2013.

[31] ACI 318-11, Building Code Requirements for Structural Concrete and Commentary, American Concrete Institute, Farmington Hills, MI, USA, 2011.

[32] V. K. Papanikolaou and A. J. Kappos, "Confinement-sensitive plasticity constitutive model for concrete in triaxial compression," International Journal of Solids and Structures, vol. 44, no. 21, pp. 7021-7048, 2007. 
[33] J. B. Mander, M. J. N. Priestley, and R. Park, "Theoretical stress-strain model for confined concrete," Journal of Structural Engineering, vol. 114, no. 8, pp. 1804-1826, 1988.

[34] J. B. Mander, M. J. N. Priestley, and R. Park, "Observed stressstrain behavior of confined concrete," Journal of Structural Engineering, vol. 114, no. 8, pp. 1827-1849, 1988.

[35] L.-H. Han and Y.-F. An, "Performance of concrete-encased CFST stub columns under axial compression," Journal of Constructional Steel Research, vol. 93, pp. 62-76, 2014.

[36] T. Yu, J. G. Teng, Y. L. Wong, and S. L. Dong, "Finite element modeling of confined concrete-I: Drucker-Prager type plasticity model," Engineering Structures, vol. 32, no. 3, pp. 665679, 2010.

[37] T. Yu, J. G. Teng, Y. L. Wong, and S. L. Dong, "Finite element modeling of confined concrete-II: plastic-damage model," Engineering Structures, vol. 32, no. 3, pp. 680-691, 2010.

[38] Z. Han, X.-Q. Wang, and B. Uy, "Stress-strain curves of structural and reinforcing steels after exposure to elevated temperatures," Journal of Materials in Civil Engineering, vol. 25, no. 9, pp. 1306-1316, 2013. 